\title{
Fabrication of Microfluidic Devices for Emulsion Formation by Microstereolithography
}

\author{
Max J. Männel (D), Elif Baysak (D) and Julian Thiele *(D) \\ Leibniz-Institut für Polymerforschung Dresden e.V., Hohe Str. 6, 01069 Dresden, Germany; \\ max5191max@googlemail.com (M.J.M.); baysak@ipfdd.de (E.B.) \\ * Correspondence: thiele@ipfdd.de; Tel.: +49-351-4658492
}

Citation: Männel, M.J.; Baysak, E.; Thiele, J. Fabrication of Microfluidic Devices for Emulsion Formation by Microstereolithography. Molecules 2021, 26, 2817. https://doi.org/ $10.3390 /$ molecules 26092817

Academic Editor:

Goran T. Vladisavljević

Received: 24 February 2021

Accepted: 27 April 2021

Published: 10 May 2021

Publisher's Note: MDPI stays neutral with regard to jurisdictional claims in published maps and institutional affiliations.

Copyright: (c) 2021 by the authors. Licensee MDPI, Basel, Switzerland. This article is an open access article distributed under the terms and conditions of the Creative Commons Attribution (CC BY) license (https:// creativecommons.org/licenses/by/ $4.0 /)$.

\begin{abstract}
Droplet microfluidics— the art and science of forming droplets-has been revolutionary for high-throughput screening, directed evolution, single-cell sequencing, and material design. However, traditional fabrication techniques for microfluidic devices suffer from several disadvantages, including multistep processing, expensive facilities, and limited three-dimensional (3D) design flexibility. High-resolution additive manufacturing-and in particular, projection microstereolithography $(\mathrm{P} \mu \mathrm{SL}$ ) - provides a promising path for overcoming these drawbacks. Similar to polydimethylsiloxane-based microfluidics 20 years ago, 3D printing methods, such as P $\mu$ SL, have provided a path toward a new era of microfluidic device design. P $\mu$ SL greatly simplifies the device fabrication process, especially the access to truly 3D geometries, is cost-effective, and it enables multimaterial processing. In this review, we discuss both the basics and recent innovations in P $\mu S L$; the material basis with emphasis on custom-made photopolymer formulations; multimaterial 3D printing; and, 3D-printed microfluidic devices for emulsion formation as our focus application. Our goal is to support researchers in setting up their own P $\mu$ SL system to fabricate tailor-made microfluidics.
\end{abstract}

Keywords: projection micro-stereolithography; microfluidics; droplets; emulsions; three-dimensional; 3D printing; additive manufacturing

\section{Introduction}

Microfluidics is a versatile tool for analytical chemistry, system integration, and material design, with droplet microfluidics being one of the most prominent examples. Microfluidics focuses on the manipulation and generation of monodisperse droplets inside microchannels [1]. Microfluidic droplet formation has been used extensively for manufacturing advanced materials [2], in drug delivery [3], and in food applications [4]. Conventionally, microfluidic devices are fabricated using a combination of photo- and soft lithography [5], glass-capillary assembly [6], hot embossing [7], and injection molding [8,9]. However, these techniques share several drawbacks. They are time-consuming and require experienced users and a nearly dust-free environment for their successful fabrication. Moreover, to achieve complex three-dimensional (3D) microchannel structures, multistep processes are commonly required to build up 3D microchannels layer-by-layer. Finally, in microchannel systems that only extend in a single plane, the microchannel surface needs to be tailored for individual applications, e.g., emulsion formation with tailored compartmentalization.

Likewise, the materials conventionally used in microfluidic device fabrication suffer several disadvantages. Polydimethylsiloxane (PDMS) swells in many organic solvents, whereas poly(methyl methacrylate) (PMMA) exhibits both poor chemical resistance and poor gas permeability, which is a key requirement for culturing cells [10]. Cyclic olefin copolymers may lack sufficient bonding [11], and parylene can suffer from poor adhesion in wet environments [12]. These shortcomings of both fabrication methods and material properties have hampered the critical step of transitioning microfluidics into industrial 
applications. Thus, a sustained need exists for a fabrication method that overcomes these drawbacks and offers reliable microfabrication covering a broad range of material properties and microchannel architectures.

In recent years, additive manufacturing (AM), which is also referred to as $3 \mathrm{D}$ printing, has attracted intensive attention as a new fabrication method for microfluidic devices. It offers several advantages over the aforementioned conventional fabrication methods. A large library of materials is available for AM, and support materials can be easily removed (e.g., by cutting or dissolution in solvents). In addition, AM requires no specialized cleanroom facilities that provide a dust-free environment, and state-of-the-art commercial $3 \mathrm{D}$ printers have small footprints. Furthermore, the digitalization of flow cell designs has opened new opportunities for the simple distribution of data and designs, which makes them accessible to a wide range of consumers worldwide. AM has the potential to become the dominant flow-cell fabrication method in microfluidics because of these advantages. Several excellent reviews have already highlighted the potential of AM in microfluidic device fabrication [13-15]. In the present review, we specifically focus on one high-resolution AM technology—projection micro-stereolithography (P $\mu \mathrm{SL})$ —and its application in droplet microfluidics. With further advances in material design, 3D-printer

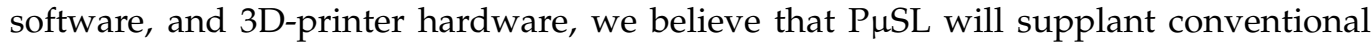
flow-cell fabrication methods within the next few years.

\section{Micro-Stereolithography}

Several 3D printing technologies have been used for microfluidic device fabrication, including extrusion-based fused deposition modeling (FDM) [16] and direct ink writing (DIW) [17], multijet modeling (MJM) [18], two-photon polymerization (2PP) [19], and $\mathrm{P} \mu \mathrm{SL}$ [20], each with a distinct set of advantages and drawbacks (Scheme 1). For instance, although extrusion-based printing is widely used because of its experimental simplicity, a key requirement is that the material be a thermoplastic. FDM is not suitable for highthroughput fabrication using a single print head because it involves the placement of fluidized material at one individual position at a time. By contrast, in $\mathrm{P} \mu \mathrm{SL}$, the whole layer is illuminated and polymerized simultaneously. However, the speed of FDM can be improved through the use of several print heads that are assembled into an array. In addition, the diameter of the extrusion nozzle largely controls the minimal process resolution, which cannot be simply exchanged. MJM printing is based on a photocurable polymer, has a high resolution with a reported channel width of $200 \mu \mathrm{m}$ [18], and multimaterial printing can be easily implemented [21]. However, the relatively high cost of the associated printers may hinder the broader application of MJM printing. 2PP provides the same resolution that is achieved with conventional photolithography, e.g., for microfluidic master device fabrication. It requires a laser system in which the energy of two photons is combined to initiate the polymerization of a resin. Because of the nature of this process, the photopolymerization is confined to the focal plane of the laser, and the photopolymerization is induced by moving the focal point of the beam [22]. A Ti:sapphire system with a typical repetition rate between $1 \mathrm{kHz}$ and $80 \mathrm{MHz}$ is the most common laser source [23]. In this process, $2 \mathrm{PP}$ addresses one voxel after another; the high frequency of the laser beam enables this process to print a structure in a nearly continuous fashion. However, 2PP is likewise time-consuming and it requires transparent liquids, which largely precludes the use of materials that are loaded with light-scattering additives, such as ceramic nanoparticles. In addition, 2PP systems are not only high-end, but also high-cost, which is not affordable for many research groups. We recommend two excellent reviews for readers who are interested in further details of $2 \mathrm{PP}[24,25]$. 

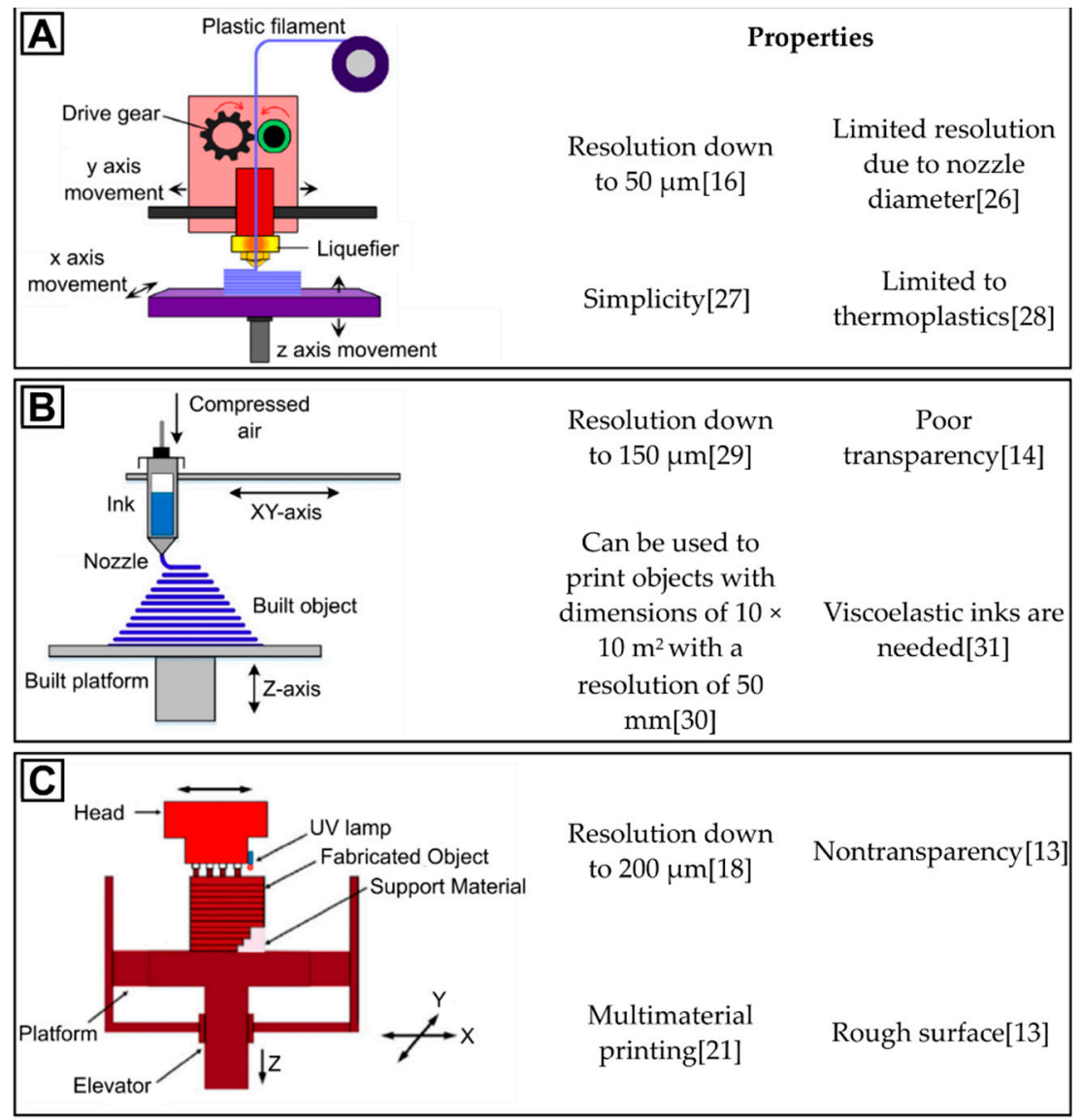

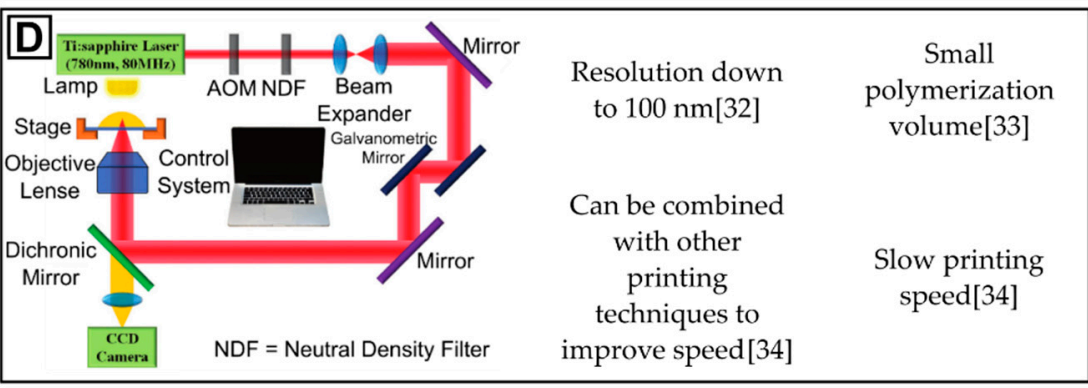

Elesolution down
Smooth surface
finish[36]

Scheme 1. Refs. [26-38] 3D-printing techniques and their characteristics properties: (A) Fused deposition modeling (adapted with permission from Akil et al. [39]), (B) direct ink writing (adapted with permission from Peretyagin et al. [40]), (C) multijet modeling (adapted with permission from $\mathrm{Xu}$ et al. [41]), (D) two-photon polymerization (adapted with permission from $\mathrm{Xu}$ et al. [42]), and (E) projection micro-stereolithography (adapted with permission from Zhang et al. [35]).

$\mathrm{P} \mu \mathrm{SL}$ has garnered intensive attention in the field of microfluidic device fabrication, because it is capable of providing high resolution with a small minimal feature size in the range from $20 \mu \mathrm{m}$ to several hundred micrometers, is compatible with a diverse material library (e.g., for achieving tailored transparency), and is rapid as well as inexpensive 
(commercial P $\mu S L$ printers are available for less than 10,000 USD). Section 3.2. provides a detailed description of parameter control in P $\mu S L$. The laser scanner in a stereolithography (SL) system is replaced with either a liquid crystal display (LCD) [43], a digital micromirror

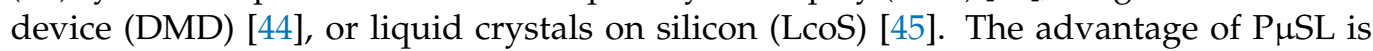
that any design is printed layer-by-layer instead of individually addressing one voxel at a time, which enables a higher printing speed than can be achieved with standard SL $[35,46]$. We recommend the recent review by Ge et al. for readers that have more interest in the resolution of the different printing techniques [47].

Before a discussion the details of microfluidic device design for droplet formation via $\mathrm{P} \mu \mathrm{SL}$, in the following section we highlight recent advances in P $\mu \mathrm{SL}$, provide an overview of custom-made 3D printers based on P $\mathrm{SL}$ as well as "homemade" photopolymer formulations, and highlight developments in multimaterial printing using P $\mu S L$.

\subsection{Recent Innovations in Additive Manufacturing of Microscale Polymer Structures}

Sochol et al. highlighted SL as promising technology for fabricating microfluidic devices capable of manufacturing sub-100 $\mu \mathrm{m}$ microchannels [48]. Different approaches have also been proposed to further reduce the processing time in SL printing from hours to even minutes. Figure 1 shows the processes of continuous liquid interface production (CLIP), 2PP, and computed axial lithography (CAL), which are currently the most prominent examples in this field. Newly introduced xolography technology is also promising for high-resolution printing with reduced production times (Figure 1).

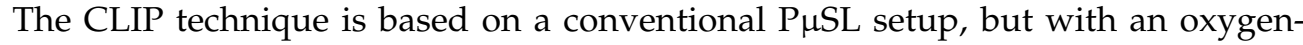
permeable window at the bottom of the resin vat, which inhibits free-radical photopolymerization due to atmospheric oxygen. The oxygen forms an uncurable layer (dead zone) between the oxygen-permeable window and the resin. This dead zone is reloaded with fresh photopolymer by the movement of the build platform, thereby obviating the need for an iterative layer-by-layer process. CLIP also enables continuous 3D production with a tailored surface finish. For instance, DeSimone and coworkers printed layer-less 3D gyroid and argyle structures at a print speed of $500 \mathrm{~mm} \mathrm{~h}^{-1}$, achieving a height of approx. $5 \mathrm{~cm}$ in less than $10 \mathrm{~min}$ [37]. Huang et al. introduced supramolecular, biocompatible alginate/polyacrylamide shape-memory hydrogels for biomedical and tissue engineering via CLIP technology [49]. In addition, 3D-printed bioresorbable vascular scaffolds [50] and microneedles for transdermal drug delivery of therapeutics have also been recently introduced [51]. He et al. studied different machine learning techniques for modeling and predicting the proper printing speed in the CLIP process and validated their findings with experimental data [52].

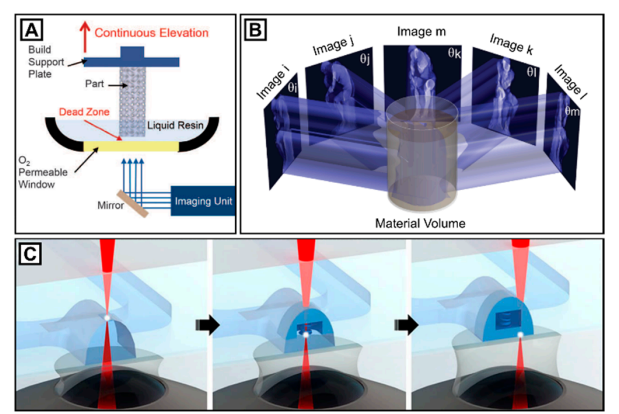

Figure 1. Recent innovations in additive manufacturing based on resin vats. (A) Schematic of continuous liquid interface production (CLIP) enabling continuous photopolymer processing at higher speed than conventional $\mathrm{P} \mu \mathrm{SL}$ due to an oxygen inhibition layer at the bottom of the resin vat. Adapted with permission from Tumbleston et al. [37] (B) Computed axial lithography (CAL) system based on computed 3D exposure of a photoresponsive material from different angles. Adapted with permission from Kelly et al. [53] (C) Illustration of in situ direct laser writing (isDLW). Focused femtosecond laser pulses, the spatially controlled photopolymerization, and the cured photomaterial are represented as red, white, and blue, respectively. Adapted with permission from Lamont et al. [54]. 
2PP, which is also known as direct laser writing (DLW), can be classified into two subcategories: in situ DLW (isDLW) [54-56] and dip-in DLW [57]. In the isDLW process, conventionally manufactured microfluidic channels can be filled with a photocurable liquid phase, followed by DLW printing inside the microchannel. In the dip-in DLW process, a liquid photoresist itself is used as the immersion liquid between a microscope lens and a substrate, which enables both millimeter-scale overall heights and submicrometer feature sizes. As an example of application, Giacomo et al. introduced deployable microtraps that were similar to miniaturized lobster pots to separate bacteria in a liquid suspension [58]. Dip-in DLW has also been used for designing biocages for drug delivery [59], microfluidic filtration systems for cell sorting [60], and for fabricating 3D structures comprising multiple materials [61]. 2PP is a comparatively young technology in AM. It relies on using focused femtosecond laser pulses to initiate the controlled polymerization of photocurable resins through two-photon absorption to directly write the desired pattern with an exceptionally high (sub-100 nm) resolution [56,62,63]. However, 2PP has drawbacks that are related to its limited printing volume and lengthy processing time. Thus, rather than manufacturing a total device via $2 \mathrm{PP}$, researchers often combine this technology with other material processing techniques, e.g., to fabricate parts of flow cells at high resolution [15,64]. Recently, the group of Chen developed a femtosecond laser projection technique, which improved the process time by parallelized printing [34].

The third example is CAL, which was inspired by computed tomography, in which 2D image projections are constructed through a material from different angles. Using this concept to illuminate a photopolymer formulation enables polymer materials to be manufactured in a volumetric fashion [53]. The photocurable material prefilled into the illumination volume remains static during the photopolymerization process because of the absence of any moving part in the printing process; therefore, highly viscous resins can be processed. As another feature of CAL, prefabricated objects can be used as substrates in the printing volume, enabling step-by-step multimaterial fabrication via AM. Moreover, CAL is several orders of magnitude faster than other techniques; a centimeter-scale geometry can be printed in less than $1 \mathrm{~min}[53,65]$. However, this fairly new technique is currently unable to 3D-print hollow structures at high resolution, which would render it suitable for printing microfluidics.

Recently, Hecht et al. introduced xolography [55]. Its theoretical approach is similar to that of CAL and it relies on volumetric 3D printing $[34,66,67]$. The authors used a dualcolor illumination technique to induce local polymerization by intersecting light beams of different wavelengths in combination with photoswitch molecules. They reported that their approach has a resolution that is ten times greater than that of CAL, and it is five orders of magnitude faster than 2PP. On the basis of their initial report [55], this technique is promising for combining both high resolution and fast processing, but has not yet been evaluated for use in the field of microfluidics.

\subsection{Custom-Made P $\mu S L 3 D$ Printers and Photopolymer Formulations}

While commercially available $\mathrm{P} \mu \mathrm{SL}$ printers and resins have greatly simplified the first implementation of AM in microfluidic device fabrication, the current trend favors custom-made solutions on both the process side and material side. The advantages of custom-made printers and resins over commercial ones are obvious. For instance, not all commercial P $\mu$ SL printers can process homemade resins because of built-in restrictions, e.g., to promote the distribution of photopolymer formulations from the printer's manufacturer. Whereas an all-in-one solution of a resin library and a P $\mu$ SL printer by a vendor may be beneficial for new users in the field of P $\mu$ SL because of the expected perfect adaption of resin properties to the printing process, explorative research will likely require opensource solutions. Moreover, the ability to control the material properties of 3D-printed objects is rather limited because the exact composition of most commercial resins for P $\mu \mathrm{SL}$ is unknown. For instance, many commercial resins only provide limited transparency because of nanoparticles inside the photopolymer formulation, whereas transparency is 
mandatory when producing microfluidic devices that enable flow-inspection experiments using UV-Vis-based optical techniques.

These disadvantages have motivated researchers to develop custom-made solutions at both the 3D-printer and resin level to gain full control over essential printing and material parameters, such as the process speed, multimaterial-processing capability, minimal feature size, transparency, elasticity, and biocompatibility. In 2012, Zheng et al. proposed a custombuilt $\mathrm{P} \mu \mathrm{SL}$ printer with a resolution of $1.3 \mu \mathrm{m}$ per pixel at the focal plane [45]. Their system was based on LcoS, and the exposure energy of the LED source ranged from $1 \mathrm{~mW} \mathrm{~cm}{ }^{-2}$ to $100 \mathrm{~mW} \mathrm{~cm}{ }^{-2}$. With this setup, complex 3D structures, such as tetradecahedrons, were successfully manufactured. Gong et al. reported a custom-made $\mu$ SL printer based on a DMD that provided a lateral accuracy of $7.6 \mu \mathrm{m}$ and used a resin formulation to fabricate flow channels with a cross-section of $18 \mu \mathrm{m} \times 20 \mu \mathrm{m}$ [68]. In 2019, Najafi and coworkers [69] introduced a P $\mu$ SL process with a lateral resolution of not more than $5 \mu \mathrm{m}$ and a reduced overall printer size as compared with that of Gong et al. [68]. They then used the customized P $\mu \mathrm{SL}$ printer to manufacture helical and hollow structures as a proof-ofprinciple to provide micron-scale polymer objects with complex geometry [69]. A common feature of the aforementioned custom-made solutions is that they provide open process parameters and are not restricted in their choice of material, thus enabling the user to tailor physicochemical and mechanical material properties for a target application.

In general, the typical material basis for any of the aforementioned examples in $\mathrm{P} \mu \mathrm{SL}$ is a photopolymer formulation (also known as a resin) that consists of a monomer or macromer with functional groups that can be polymerized or crosslinked, a photoinitiator that starts the polymerization process, a crosslinker that ensures sufficient crosslinking and mechanical stability of the 3D-printed part, a radical quencher, and a UV-absorber (e.g., a photosensitizer) to control the expansion of polymerization in the $Z$ - and lateral directions. The choice of these resin components determines the material properties of the 3D-printed part, but also its functionality. For example, transparency, minimal feature size/resolution in the micrometer range, solvent resistance, and tailorable surface wettability are critical requirements for a material to be suitable for the P $\mu$ SL printing of microfluidic devices. In general, with the introduction of homemade photopolymer formulations, these properties can be directly addressed. However, custom-made resins in 3D printing are not only interesting for microfluidic device fabrication, but also for robotics [70], self-healing objects [71], and electrically conductive parts [72], or for designing pneumatic grippers [73]. Critical parameters for tailoring resin properties, such that they are ready-to-use in P $\mu \mathrm{SL}$ printing, and for individual applications in microfluidics, are discussed in greater detail in Section 3.

\subsection{Multimaterial Micro-Stereolithography}

AM holds great promise for the single-step processing of functional materials. However, its potential is diminished by the fact that, although P $\mu$ SL is a versatile tool for implementing flow cells with unique microchannel networks and complex 3D geometries, most examples rely on the use of single materials, which leads to monolithic flow cells with uniform material and microchannel properties. Although uniform material properties across a flow cell may provide sufficient functionality, e.g., to realize single-phase or multiphase continuous flow, the range of applications of microfluidic devices extends beyond these applications. For instance, multiparametric cell culturing, the design of multicompartment materials, such as (double) emulsions, biomolecule separation [74], and system integration in sensing applications may require tailored surface properties of the flow cell, particularly with spatial control. Conventionally, tailoring these surface properties, also with spatial control, commonly requires post-processing of the microchannel surface, e.g., by applying functional coatings.

Thus, the design of advanced multifunctional microfluidic devices may require a shift toward processing multiple materials, ideally on a single P $\mu$ SL platform. Although the implementation of multimaterial 3D printing has been realized in other $\mathrm{AM}$ techniques 
(e.g., DIW [75], FDM [76], and jetting [77]), only a few solutions for resin-vat-based polymerization techniques (e.g., multimaterial projection micro-stereolithography (MM P $\mu \mathrm{SL})$ ) are known. In general, three different approaches have been developed: (I) vat switching [78,79], (II) in situ material exchange through dynamic fluid control [38], and (III) the assembly of pre-printed parts (Figure 2) [80-82].
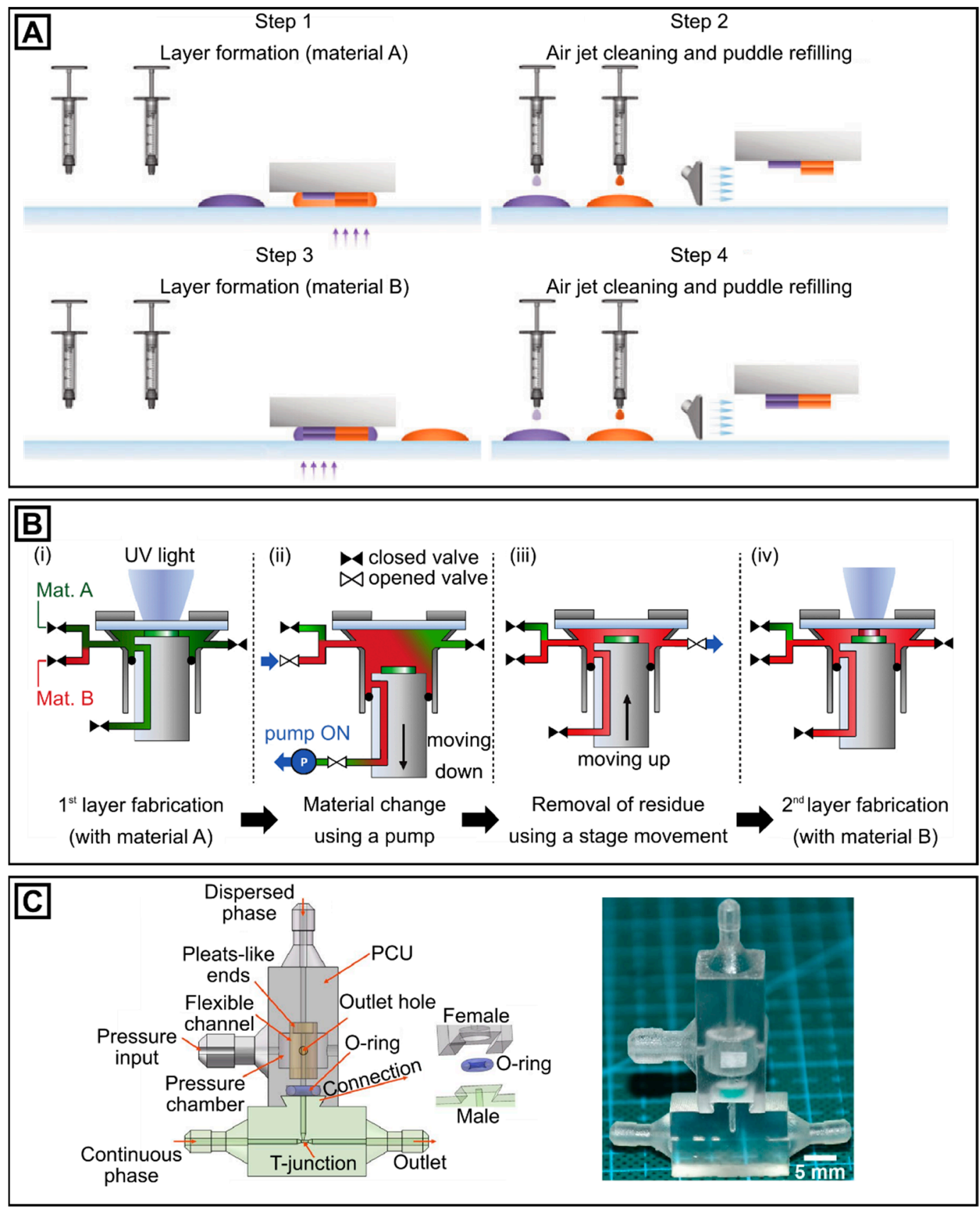

Figure 2. Multimaterial 3D printing based on P $\mu$ SL. (A) Two different materials are processed together by a modified vat switching system. Syringes control the amount of resin placed on the glass. Pressurized air removes uncured resin to avoid introducing surface impurities when switching between resins. Adapted with permission from Ge et al. [79] (B) Resin exchange in multimaterial P $\mu$ SL within a few seconds using dynamic fluid control of different resins within an integrated flow cell replacing the conventional resin vat. Adapted with permission from Han et al. [38] (C) Pre-fabricated microfluidic parts made from different materials assembled into a functional flow cell for emulsion formation. Adapted with permission from Ji et al. [80]. 
In 2011, Choi and coworkers introduced a custom-made 3D printer for processing different materials in a multimaterial approach [78]. They implemented a rotating-vat carousel system with four vats and successfully printed 3D structures from three different commercial resins. On the basis of this approach, Kowsari et al. constructed a novel digital light processing (DLP)-based micro-stereolithography approach, where different resins are placed on a glass plate, and the plate is moved to the printing position [79]. Different resins are processed, depending on the coordinates to which the plate moves (Figure 2A). The authors also shortened the time-consuming step of cleaning the printed layers and the glass plate by applying an air jet that removes the uncured resin within seconds before switching to the next resin; they claimed that their method using an air jet is approx. 56\% faster than other approaches that use cleaning solutions.

In 2019, Han et al. proposed another solution for multimaterial P $\mu$ SL printing [38]. In their system, a flow cell surrounding the printing platform is integrated with different microfluidic inflow ports-one for each resin. After a layer is printed with resin A, the flow cell is flushed with resin B to replace resin A within seconds. The purity of the printed layer with resin B was greater than 95\%. This method was not only used for the 3D-printing of (nanoparticle-loaded) acrylate-based resins, but also for hydrogels. The researchers obtained multiresponsive objects with a layer thickness of $150 \mu \mathrm{m}$ by combining different functional hydrogels being thermoresponsive and electroactive.

The third example of multimaterial processing of polymers that can be used in multifunctional microfluidic device design does not rely on MM P $\mu \mathrm{SL}$, but it contributes to the idea of multifunctional 3D-printed devices and is, therefore, discussed herein. The idea of prefabricated discrete elements assembled after the printing process was first proposed by Malmstadt and coworkers in 2014 [81]. The authors designed a library of different microfluidic elements and connectors that were reversibly connected, with the objective of fabricating truly complex microchannel systems. With these microfluidic elements, the authors assembled flow-focusing devices and T-junctions for the production of emulsions with a channel cross-section of $750 \mu \mathrm{m}$. Following this approach, Duan et al. proposed a similar system that also incorporates different materials and takes different printing platforms into account [80]. As a major application, they used an elastic material for the pneumatic control of emulsion formation.

Although the aforementioned reports have contributed to the implementation of MM $\mathrm{P} \mu \mathrm{SL}$, high-resolution multimaterial 3D printing, in particular, remains an ongoing challenge.

\subsection{Static Materials vs. Switchable and 4D Materials}

$\mathrm{P} \mu \mathrm{SL}$ printing is based on the idea of deconstructing a 3D computer-aided design (CAD) into 2D layers that are then added onto one another to yield the desired 3D object [83]. Although AM has evolved regarding accuracy, multiple material printing capabilities, and high printing speeds, conventional products, such as microfluidic devices, behave statically. Thus, although materials may be highly functional because of a complex microchannel architecture or a likewise complex surface functionalization, conventional materials in AM cannot respond to a change in environmental conditions over time. In so-called fourdimensional (4D) material printing, this time axis is considered in material functionality to obtain products with truly programmable properties, rather than static performance. Such a 3D-printed material can continuously adapt over its lifecycle, e.g., to mechanical changes and temperature, thus circumventing the need to redesign materials for individual sets of environmental conditions [84,85]. 4D materials can detect environmental stimuli and generate an advantageous response to the stimulus by changing either their material properties or their geometries, paving the way toward smart materials [86]. The external stimulus can be exerted physically, chemically, or biochemically. The response can be uniform regarding degradation, shrinkage, swelling, or a color change $[87,88]$. In addition, 4D-printed materials can be classified according to the type of external stimulus as thermo-, moisture-, photo-, electro-, magneto-, or pH-responsive. Applications that in- 
volve 3D-printed 4D materials include smart valves [89], microgrippers [90], drug delivery systems [91], energy-harvesting and storage systems [92], and functional organs [85,93].

Relevant examples in the field of 4D-printed biosciences include photoinitiated drug delivery [94], thermoresponsive surfaces for tissue printing [95], and magnetically actuated inchworm-inspired, biomimetic robots [96]. Along these lines, 4D printing has also influenced biomaterial design, where $4 \mathrm{D}$ materials have been used to more closely reflect the dynamic nature of living tissues (e.g., in the design of smart stents and implants) and organ printing (e.g., kidney, heart, and liver elements) [86,97-99].

Although $4 \mathrm{D}$ printing has been a revolution in the manufacture of dynamic structures, it commonly relies on conventional polymer materials that are known for their responsiveness and adaptiveness to enable the 3D-printing of $4 \mathrm{D}$ materials. One of the simplest examples is a material's response toward humidity and salt concentration, as observed in, for example, 3D-printed hydrogels [97-100]. Another example is the plasmonic heating of 3D-printed polymer materials that convert light energy into heat, and then undergo a temperature-induced phase transition [99,101]. Furthermore, pH-responsive materials can swell or shrink in response to $\mathrm{pH}$ changes in the surrounding environment [102]. Among these materials, poly(N-isopropyl acrylamide) (PNIPAAm) is a prime example $[103,104]$.

Quanjin et al. carried out a SWOT analysis of 3D and 4D printing technologies, evaluating their strengths, weaknesses, opportunities, and threats [105]. Their analysis indicated that the 3D printing of adaptive-responsive $4 \mathrm{D}$ polymer materials has the potential to soon provide highly engineered, intelligent materials that exhibit desirable changes in size, shape, and porosity, among other properties, because of the applied or recognized/identified triggers for future programmable materials that are fabricated by AM.

\section{Requirements for $\mathrm{P} \mu \mathrm{SL}$ Processability}

The different printing techniques based on $\mathrm{P} \mu \mathrm{SL}$, homemade 3D printers and resins, along with the progress toward innovations in multimaterial printing, have already been discussed. Before focusing on applications, we will detail the polymerization techniques in $\mathrm{P} \mu \mathrm{SL}$ and the resins themselves.

First, we need to distinguish between mass polymerization and solution polymerization. In the first case, the monomer itself is liquid such that this process does not require a solvent; in the latter case, the material is dissolved in a solvent before being used for 3D printing. In applications where solution polymerization is not based on an aqueous reaction mixture (e.g., 3D-printing of biocompatible hydrogels), but requires cytotoxic solvents that demand efficient post-processing to remove any solvent residues, bulk polymerization may be advantageous. Additionally, because of potential chain-transfer reactions with the solvent, the 3D-printed parts may be mechanically inferior as a consequence of incomplete crosslinking [106-109]. This review focuses on the vast field of mass polymerization of resins, although examples exist where solution polymerization has been used. For example, Wilking and coworkers proposed the 3D printing of microfluidic hydrogels containing spiral channels with submillimeter-scale cross-sections, where the spiral channels can be used to mimic the complex vasculature of living organisms [110].

\subsection{Polymerization Techniques in $P \mu S L$}

SL is based on the photopolymerization of photosensitive monomers or macromers in the presence of a photoinitiator or a photoinitiator system that translates photolytic energy into reactive species, such as a radical or cation, triggering chain growth of the monomer or macromer into a polymer network and 3D-printed object, respectively [111-115]. Acrylate and methacrylate monomers or oligomers, as well as vinyl compounds, are commonly processed in SL-based printing via a radical chain-growth polymerization mechanism with initiation, propagation, and termination steps $[111,113,115,116]$. In addition, alkyl thiols can react in thiol-ene [116-118] (Figure 3A) or thiol-yne [119] (Figure 3B) addition reactions, which have been used for the $3 \mathrm{D}$ printing of soft robotics and self-healing materials [120]. Moreover, highly crosslinked networks are also accessible using multifunctional 
alkynes instead of vinyl monomers via a secondary thiol addition reaction with excess thiol groups [113,115]. Such 3D-printed structures could be degraded and erased under mild conditions with a well-defined trigger, such as ethanolamine, as Zieger et al. demonstrated using DLW [121]. The same research group also demonstrated that thioaldehydes can form network structures with thiol linkers, leading to disulfide-bridged polymer networks that can again be degraded via a thiol-disulfide exchange reaction with dithiothreitol [122].
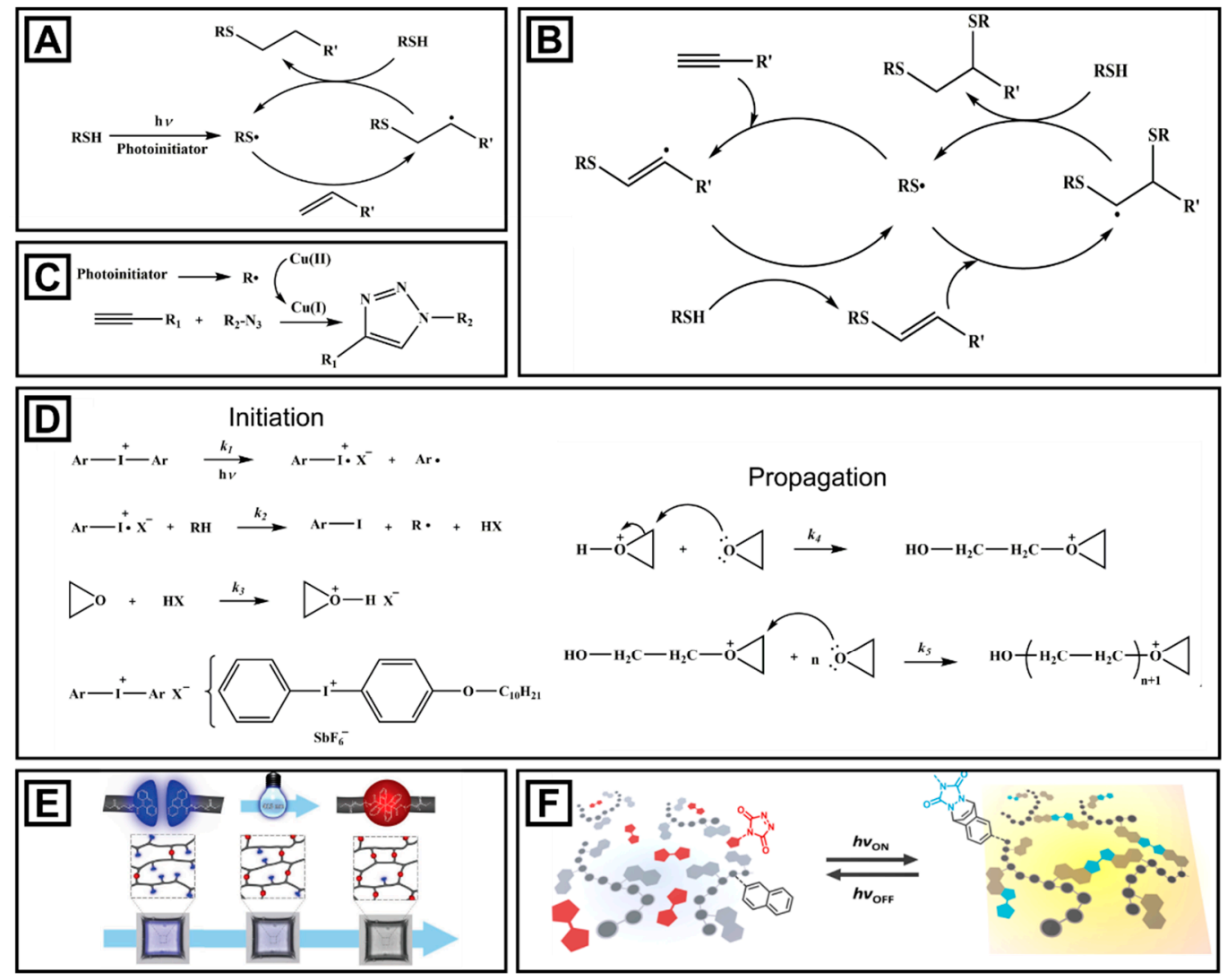

Figure 3. Potential crosslinking mechanisms in 3D printing: (A) thiol-ene (adapted with permission from Konuray et al. [123]), (B) thiol-yne (adapted with permission from Konuray et al. [123]), (C) copper-catalyzed azidealkyne reaction (adapted with permission from Konuray et al. [123]), (D) cationic photopolymerization of epoxy monomers (adapted with permission from Crivello et al. [124]), and (E) cycloaddition dimerization of anthracene moieties (adapted with permission from Gernhard et al. [125]). (F) Schematic of covalent crosslinking of naphthalene containing PMMA polymers with bifunctional triazolinedione cross-linker in P $\mathrm{SL}$ by visible-light-driven cycloaddition (adapted with permission from Houck et al. [126]).

Whereas free-radical polymerization conventionally provides chemically inactive polymer structures, the use of a living polymerization mechanism in $\mathrm{P} \mu \mathrm{SL}$ enables the activation or deactivation of further polymerization of a 3D-printed object, which, in turn, enables the on-demand addition of features to an existing object. Jin and coworkers introduced both a photocontrolled reversible addition fragmentation chain transfer (photo-RAFT) polymerization [127] and a photoelectron/energy transfer reversible addition-fragmentation chain-transfer (PET-RAFT) polymerization [128] in DLW printing technology.

Epoxides and oxetanes can be cured through cationic photopolymerization, where thermally stable aryl iodonium and sulfonium salts act as cationic photoinitiators, which generate a mixture of cations, radical cations, and radical intermediates under UV irradiation $[113,129,130]$. Lantean et al. combined cationic polymerization with radical mechanisms through a hybrid monomer that contains both acrylic and epoxy functionalities to demonstrate the reactivity of the species under irradiation and evaluated the mechanical properties of the resultant prints [131]. Additionally, Zhao et al. introduced 
dual photopolymerization systems, such as acrylate silicone-epoxy hybrid resins in stereolithography printing, to achieve photopolymerization using a combination of free-radical and cationic polymerization mechanisms [132].

Light-induced step-growth polymerization methods do not necessarily require an initiator; they can proceed via a reaction of di- or trifunctional monomers, e.g., in photoinitiated azide-alkyne cycloaddition reactions (Figure 3C), as studied by Bowman and coworkers [133]. However, although this method can be coupled with spatiotemporal control over polymer material formation [133], its use in additive manufacturing has not yet been investigated in detail. Nonetheless, photoinitiated azide-alkyne chemistry has been used for post-processing surfaces of 3D-printed objects [134].

Diels-Alder (DA) reactions describe reversible cycloadditions between a conjugated diene and a dienophile under mild conditions (even room temperature [135]); however, at elevated temperatures, the retro-DA reaction occurs, which causes cleavage of the cyclic adduct (e.g., $110-140{ }^{\circ} \mathrm{C}$ ) [136]. Li et al. reported P $\mu$ SL printing of shape-memory and recyclable polyurethanes based on DA reactions [136]. They first prepared polyurethane acrylate with a DA adduct and then prepared photopolymer formulations with reactive diluents and photoinitiators to obtain a series of resins.

In another example of a photo-DA reaction, triazolinediones (TADs) were reacted with naphthalenes, yielding an unprecedented dynamic polymer system that could reversibly switch from a covalently crosslinked material in the presence of light to a viscoelastic liquid (Figure 3F) [126]. Houck et al. implemented a backbone functionalization of poly(ethylene glycol) with TADs, which could form polymer networks under UV irradiation in the absence of a photoinitiator. Moreover, the 3D-printed structure could be readily erased by water without requiring a change to acidic or basic reaction conditions [137]. In another set of cycloadditions, anthracene moieties were linked in a photodimerization via [4+4] cycloaddition under irradiation $(\lambda>300 \mathrm{~nm})$ to yield DLW-printed polymer objects in the dark (Figure 3E) [125]. Finally, Khademhosseini and coworkers recently demonstrated the careful selection of crosslinking methods to balance the mechanical and chemical properties, and the response of living cells to 3D-printed polymer hydrogels [138].

The combination of UV light, radicals, and potentially uncured, cytotoxic resin components in 3D-printed polymer materials results in a challenging environment for advanced applications in cell biology and cell-free biotechnology because stereolithography techniques generally rely on a UV-light-induced crosslinking mechanism of photopolymer formulations. Thus, the use of resins and processing conditions that are cytocompatible is an ongoing challenge in $\mathrm{P} \mu \mathrm{SL}$ printing.

\subsection{Processing of Resins}

A common feature of the aforementioned polymerization mechanisms is that they are suitable for use in P $\mu$ SL. However, the radical polymerization of (meth)acrylates is mainly used with microchannel resolution down to $20 \mu \mathrm{m}$. However, achieving full control over the actual printing process of homemade resins requires not only knowledge about the polymerization mechanism, but also about the process parameters of the 3D printer (e.g., light intensity and exposure time) as well as the physicochemical properties and composition of the resin (e.g., concentration of components and additives, overall viscosity, and oxygen concentration). A good understanding of this complex parameter space is the basis by which the penetration depth of light into a photopolymer formulation-and, thus, the minimum feature size of a P $\mu$ SL-printed object, such as a microfluidic device-can be controlled. Scheme 2 shows an overview of the most important parameters, which are, which are discussed in the following paragraphs. 


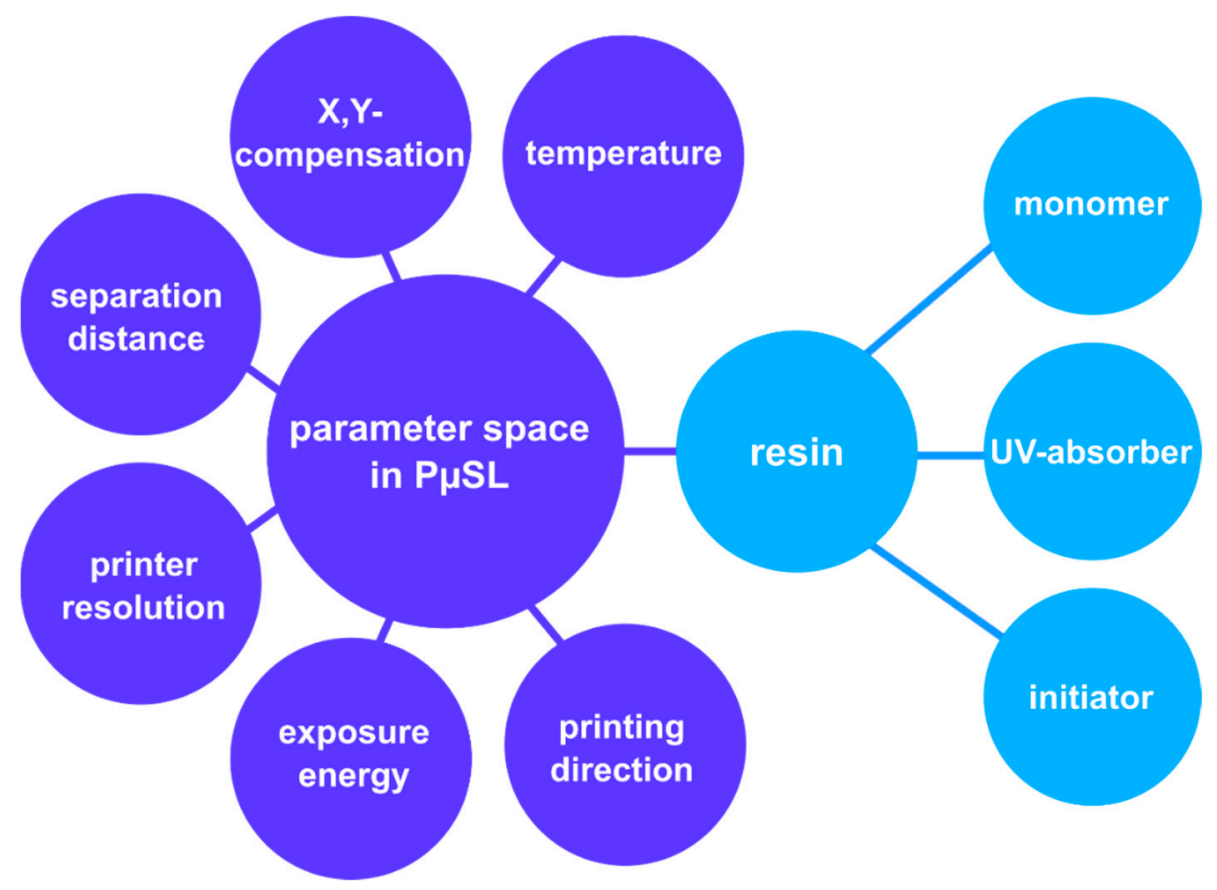

Scheme 2. Potential parameter space in P $\mu$ SL printing of, e.g., microfluidic devices.

The parameter space in P $\mathrm{SL}$ is manifold; however, some of the parameters are considered to have more impact on the printing resolution than others. Here, we focus on the parameters that potentially increase the resolution of the 3D-printed structures the most, being set by the 3D-printing platform (intrinsic parameter) and the resin (extrinsic parameter). In detail, the exposure energy (I), separation distance (II), printer resolution (III), X, Y-compensation (IV), temperature (V), and the printing direction (VI) are considered to be intrinsic parameters that can be adjusted well before the printing process.

(I) The exposure energy is the result of the multiplication of the light intensity of the printer and the illumination in the printing process. It not only initiates the polymerization process itself, but also influences the polymerization depth of the material and, therefore, the layer thickness. For instance, with increasing the exposure energy, the polymerization depth increases and vice versa [139].

(II) The separation distance can be commonly adjusted in the 3D printer software. This parameter can also affect the dwell time of the last printed layer in atmospheric oxygen, as reported by our group in 2019 [20]. Oxygen inhibits the propagation of radical-driven polymerization, and it forms stable peroxy radicals that do not participate in the printing process and are considered to be dead-ends in the polymerization reaction [45].

(III) The lateral and vertical resolution of the printer strongly influences the printing resolution. The lateral resolution is the resolution in the $X, Y$-direction created by the optical setup-mainly the DMD and its pixel pitch — as well as by the use of optical (focusing) lenses [140]. By contrast, the vertical resolution in the Z-direction is set by the mechanical setup of the printer, and it also determines the possible layer thickness in the printing process. For example, the gap between the building platform and the transparent bottom of the vat is set to $20 \mu \mathrm{m}$. Therefore, the layer thickness is $20 \mu \mathrm{m}$, even if the polymerization depth of the resin is substantially greater, which then results in better adhesion of the before-printed layers. Nordin et al. proposed a custom-made P $\mu S L$ printer with a lateral resolution of $7.6 \mu \mathrm{m}$, which they used for 3D-printing serpentine microchannels with a cross-section of $18 \mu \mathrm{m} \times 20 \mu \mathrm{m}$ and a length of $3 \mathrm{~mm}$ [68]. Notably, the lateral resolution of the printer could not be translated into the highest resolution in a 3D-printed object because of potential overcuring and nonuniform light distribution; however, an in-depth discussion of these effects is beyond the scope of the current review [141]. 
(IV) The voxel compensation in the $X, Y$-plane is a parameter that can be specifically defined in P $\mu S L$ printers. It describes the adjustment of the grayscales of the DMD to 3D-print microstructures that, otherwise, would lead to clogging, because the designs are not consistent with the printer's lateral resolution. For example, a $25 \mu \mathrm{m}$ cross-section of a microchannel would be either $20 \mu \mathrm{m}$ or $30 \mu \mathrm{m}$ in a cross-section fabricated with a printer that provides a lateral resolution of $10 \mu \mathrm{m}$. To overcome this mismatch, a printer's grayscale can be varied from 0 (no illumination) to 127 ( $50 \%$ light intensity) to 255 (100\% light intensity, full illumination). Here, the grayscales are adjusted between 0 and 255 to provide variations in light intensity for achieving partly polymerized voxels [20].

(V) An appropriate temperature during the printing process is critical to ensure the processability of a resin. Although most low-molecular-weight resins are liquids at room temperature, some are difficult to process because of the high viscosity of the starting materials. Increasing the temperature of the printer's resin vat lowers the viscosity of the

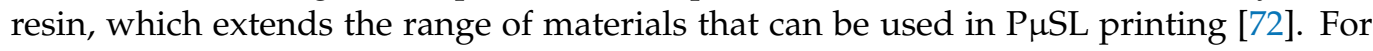
instance, to process shape-memory polymers as a viscous melt (approx. $30 \mathrm{~Pa}$ s), Magdassi et al. heated the P $\mu \mathrm{SL}$ printer's vat to $90^{\circ} \mathrm{C}$ before 3D printing objects [142]. (VI) The sixth parameter to consider in P $\mu \mathrm{SL}$ printing is the orientation of the object (e.g., microfluidic device) at the printer platform. Structures within a polymer object can be orientated either along the $Z$-axis or along the $X, Y$-plane. An orientation along the $Z$-axis was shown to be favorable for achieving a higher resolution in micron-scale 3D printing, depending on the printer's resolution and the layer thickness $[20,143]$.

Beyond these intrinsic parameters, the extrinsic parameters of the to-be-processed material itself should also be considered. A resin typically comprises monomer(s)/oligomer(s), an initiator, a UV-absorber, a radical quencher, and a crosslinker, each of which contributes to the resin's overall printability. In addition, the processability is highly dependent on the uniformity of the light intensity of the 3D printer. Lipson and Kurman showed that it is related to the curing depth $C_{\mathrm{d}}$, which is expressed by Jacob's working curve:

$$
C_{\mathrm{d}}=D_{\mathrm{p}} \ln \frac{E_{0}}{E_{\mathrm{c}}}
$$

where $D_{\mathrm{p}}$ is the polymerization depth and $E_{0}$ and $E_{\mathrm{c}}$ are the irradiation intensity and critical exposure to initiate the polymerization process, respectively [144]. Relying on this theoretical consideration, Ge and coworkers showed that the maximum light intensity is found at the center of a pixel and, therefore, results in a conical shape of the voxel [141]. Nordin et al. developed a mathematical model for the polymerization depth $z_{\mathrm{p}}$ for a given exposure time $t_{\mathrm{p}}$ :

$$
z_{\mathrm{p}}=h_{\propto} \ln \frac{t_{\mathrm{p}}}{T_{\mathrm{c}}}
$$

Here, $h_{a}=\frac{1}{\alpha}$, where $\alpha^{\prime}$ is the resin's absorption coefficient, which is unique for the chosen material, and it can be adjusted by the UV-absorber [145]. Zheng et al. and Gong et al. $[45,68]$ showed that a UV-absorber reduces the reaction rate of the polymerization reaction by limiting the number of available photons, which resulted in a reduced polymerization depth and, thereby, enabled the layer thickness to be controlled and the resolution to be optimized $[45,68]$. Notably, the optical absorption spectrum of the UV-absorber must overlap with the optical emission spectrum of the light source to provide a sufficient reduction of the reaction rate. Interestingly, it has been shown, for a resin consisting of 1,6-hexanediol diacrylate, Sudan 1, and diphenyl(2,4,6-trimethylbenzoyl)phosphine oxide, that the concentration of the photoinitiator had limited effect on the polymerization process; e.g., it did not change the polymerization depth at all at photoinitiator concentrations greater than $2 \%$ [45]. In addition, increasing the light intensity and exposure time lead to greater layer thicknesses, and to an increase in the polymerization depth, respectively.

A potential issue that is associated to the post-processing of 3D-printed materials is volume shrinkage and, thus, changes in the object's dimensions. While significant shrinkage occurs during the processing of, for example, ceramics, this challenge is almost 
negligible in P $\mu$ SL of polymer formulations. For instance, Wenjuan and coworkers showed, in 2017, that the shrinkage of their prints was less than $2 \%$ [146]. In another example, a commercial material supplier claims a shrinkage smaller than $0.5 \%$ [147].

\section{Applications of $\mathrm{P} \mu \mathrm{SL}$ in Microfluidics}

The fabrication of microfluidic devices that are based on P $\mu$ SL is discussed in greater detail later in this section; first, we briefly highlight the potential of P $\mu$ SL for fabricating microstructured polymer materials with a complex 3D geometry for other applications. Because 3D-printed materials in P $\mu$ SL often exhibit substantial toxicity due to additives, such as the UV-absorber Sudan I, they are not suitable for most biomedical applications. To address this problem, Männel et al. [148] and Warr et al. [149] developed resins that were based on poly(ethylene glycol) diacrylate (PEGDA) exhibiting sufficient cell viability and proliferation in long-term cell culture experiments. Männel et al. [148] proposed a combination of PEGDA, poly(ethylene glycol) methyl ethyl methacrylate, Sudan 1, and diphenyl-(2,4,6-trimethylbenzoyl)phosphine oxide to cultivate human umbilical vein endothelial cells for 24 days. Washing the 3D-printed object after the printing process in phosphate-buffered saline removed Sudan 1, dramatically reducing the cytotoxicity of the 3D-printed cell culturing substrates. Warr et al. [149] used a similar resin based on PEGDA and avobenzene as the UV-absorber. They washed their 3D-printed object in ethanol for $12 \mathrm{~h}$ to reduce the cytotoxicity of the material and then subjected the object to a plasma treatment to improve cell adhesion. On the other hand, Kotz et al. used a commercial SL printer for processing a photocurable silica nanocomposite to fabricate transparent fused glass devices with a resolution of approximately a few tens of micrometers. The 3D-printed parts were transformed into glass components through a stepwise heat treatment, which resulted in a smooth surface with a roughness of only a few nanometers [150].

Another field of application of P $\mu \mathrm{SL}$ toward the fabrication of complex 3D microstructures is soft robotics. For example, Boydston and coworkers built three-armed pneumatic grippers from a homemade elastomer with a minimal tensile stress of $0.104 \mathrm{MPa}$ [73]. Magdassi and coworkers formulated a homemade resin that was based on aliphatic urethane diacrylates to fabricate highly stretchable 3D-printed objects for soft robotics [72], and Peele et al. used a commercially available elastomer resin to fabricate soft actuators as a model for artificial muscles [151]. These examples highlight the broad range of applications that

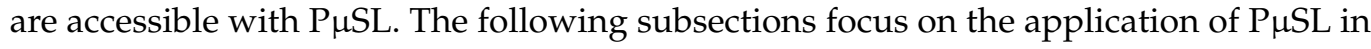
microfluidics, with an emphasis on 3D-printed microfluidic devices for forming single and double emulsions.

\subsection{Microfluidics: Applications and Functional Components}

\subsubsection{Applications in Microfluidics}

Before focusing on microfluidic devices for forming emulsions, we note other applications of microfluidics and functional microfluidic modules already realized by P $\mu$ SL. In 2018, Choi and coworkers 3D-printed a microviscometer using a stereolithography-based printer to measure blood viscosity [152]. In the same year, Zhang's group developed a hybrid modular system for generating droplets in glass capillaries. Their system comprised three parts: (I) a top module for the dispersed phase, (II) a glass capillary for emulsion formation, and (III) a bottom module for the continuous phase; components (I) and (III) were 3D-printed by P $\mu \mathrm{SL}$ [153].

The fast, efficient mixing of multiple flows is another important subfield in microfluidics. Here, the advantage of 3D printing over conventional microfluidic device fabrication methods again lies in the ability to create microchannels in different layers in a single step [154-157]. Eijkel et al. 3D-printed a microfluidic device with five inflow ports that were filled with collagen to monitor the concentration profiles of solutes to mimic targeted drug delivery [158].

Controlling the merging of microdroplets is critical for mixing small, individual volumes in chemical and biological analyses. To this end, Thoroddsen and coworkers 
3D-printed a microfluidic device to merge droplets passively via pillar blocks inside microchannels [159]. Wagner's group proposed a 3D-printed sensor system for monitoring cell growth inside microfluidic devices P $\mu$ SL-printed using the commercial resin PlasCLEAR $^{\mathrm{TM}}$ [160]. Before the actual cell-culturing experiment, the 3D-printed device was immersed in the cell culture medium for two days [160]. Similarly, Folch and coworkers developed a transparent resin based on low-molecular-weight PEGDA for the long-term culturing of sensitive neuron cells [161]. Jeon et al. used a 3D-printed cylindrical microchannel to develop an immunomagnetic flow assay for the detection of pathogenic bacteria with high sensitivity and high capacity [162,163]. In another example, Alessandri et al. introduced a microfluidic device that generates submillimeter hollow hydrogel spheres encapsulating human neural stem cells [164].

\subsubsection{Functional Components}

Focusing on functional elements in microfluidics to control fluid flow inside microchannels, such as valves and pumps, Au et al. used the commercial resin WaterShed XC $11122^{\mathrm{TM}}$ to transfer Quake's valve design [165] into 3D-printed flow cells that are suitable for cell culture [166]. The authors chose WaterShed ${ }^{\mathrm{TM}}$ because of its ability to provide transparent flow cells that do not swell in water and that meet the minimum standards for biocompatibility. However, like materials 3D-printed with other commercial resins, those 3D-printed with WaterShed ${ }^{\mathrm{TM}}$ lack resolution, which results in microfluidic channels in the range of millifluidics rather than microfluidics. Lee et al. used a homemade resin based on PEGDA to 3D-print Quake's valves to overcome the issue of limited resolution in P $\mu$ SL [167]. Membranes with thicknesses of $25 \mu \mathrm{m}$ and even $10 \mu \mathrm{m}$ were successfully fabricated, and the valves were closed pneumatically with pressures between approx. $20 \mathrm{kPa}$ and $40 \mathrm{kPa}$. In addition, arrays of 64 valves were 3D-printed in an 8-by-8 fashion to demonstrate the scalability and reliability of the fabrication approach. However, because the Young's modulus of the material was approx. $130 \mathrm{MPa}$ as compared to $>1 \mathrm{MPa}$ for PDMS [168], the authors adapted their flow-cell design to ensure sufficient sealing. Because of this poor material flexibility compared with that of PDMS, Männel et al. proposed a homemade resin based on tri(propylene glycol) diacrylate, which resulted in a reduction of the Young's modulus to approx. $15 \mathrm{MPa}$ [169]. In addition, microchannels that were 3D-printed from this homemade resin exhibited cross-sections as small as $40 \mu \mathrm{m}$, which is similar to the minimum feature size and resolution achieved in PDMS-based microfluidic devices. The authors demonstrated the applicability of their resin formulations for microfabricating two different valve designs: Quake's valves (cf. above) and a design that is based on the work of Nordin and coworkers [170]. In that original work from 2015, the authors 3D-printed valves via P $\mu \mathrm{SL}$ as a proof of concept [139]. The microchannels had a cross-section of $250 \mu \mathrm{m} \times 350 \mu \mathrm{m}$ with a single-layer valve that was closed by applying approx. $74 \mathrm{kPa}$ to deflect the membrane, which was successfully demonstrated for $800 \mathrm{actu}-$ ations. By adding a second thermally actuated initiator to their resin formulations, Nordin and coworkers further improved the durability of the valves for as many as 1,000,000 actuations [171]. Moreover, with five-pump actuation, they could use their membranes as a microfluidic pump with flow rates as high as $40 \mu \mathrm{L} \mathrm{min}{ }^{-1}$.

The aforementioned examples demonstrate that researchers have already successfully translated the design of microfluidic modules from conventional fabrication techniques into P $\mu$ SL. These modules and their material properties are critical for a wide range of microfluidic applications and they represent a decisive step for the future development of 3D-printed complex microfluidic devices.

\subsection{Single Emulsion and Double Emulsion Formation in P $\mu S L$-Printed Devices}

\subsubsection{Single Emulsion Formation}

Microfluidic devices can be operated in two fundamentally different modes: two fluids form a continuous co-flow or, in the case of distinct interfacial tension between two fluids, these fluids form a segmented flow and droplets, respectively [172]. The physics 
behind droplet formation is beyond the scope of this review; interested readers are referred to several excellent related publications [172-174].

Normally, all of the microchannels inside a microfluidic device are within the same layer when a conventional, single-layered master structure, also referred to as a planar microchannel geometry, is used. In these microfluidic devices, surface wettability may be critical to the formation of a certain type of emulsion (i.e., water-in-oil or oil-in-water). When P $\mu$ SL printing is used as the fabrication method of choice, complex 3D structures in which surface wettability becomes negligible can be achieved because a nonplanar microchannel geometry can be realized [175].

Following the idea of nonplanar devices for emulsion formation without tailored microchannel wettability, Thiele's group used the commercial resin R11 ${ }^{\mathrm{TM}}$ and a commercial P $\mu$ SL printer to fabricate monolithic microfluidic devices for droplet formation (Figure 4A) [20]. Specifically, flow cells with a microchannel cross section of $75 \mu \mathrm{m}$ for the dispersed phase and $200 \mu \mathrm{m} \times 300 \mu \mathrm{m}$ in the cross-section for the continuous phase were fabricated. The devices were used for the formation of both water-in-oil and oil-inwater emulsions inside the same devices, which is a substantial advantage of nonplanar complex 3D structures over conventionally fabricated microfluidic devices. The droplets then served as templates for forming microparticles with diameters as small as $93 \mu \mathrm{m}$ via UV-induced polymerization of a prepolymer solution inside the droplets. Zhang et al. proposed a similar approach in 2016. Here, the microchannel dimensions were larger: $600 \mu \mathrm{m}$ in diameter for the dispersed phase and $1000 \mu \mathrm{m}$ for the continuous phase [176]. While these examples are based on 3D-printed nonplanar geometries, Kim and coworkers demonstrated a planar droplet maker [43]. They showed that the diameter of the circular channel was $400 \mu \mathrm{m}$ and that water-in-oil emulsions could be formed at rates between 20 and 80 droplets per minute, depending on the flow rate ratio. Finally, they 3D-printed a multilayered microfluidic device with two flow-focusing junctions for parallel droplet formation. The inflow port of the dispersed phase was located in a different layer from the inflow port of the continuous phase, highlighting the great flexibility in 3D design.

Hwang et al. P $\mu$ SL-printed a millifluidic device with a chimney-shaped geometry consisting of a cubic bottom part and a pyramidal upper part (Figure 4B) [177]. The fluids were introduced from opposite directions for parallelization of droplet formation. Interestingly, although all of the microchannels were designed to be $1.58 \mathrm{~mm}$ in diameter, which is far from typical dimensions of microfluidic channels at first glance, depending on the flow rate ratio and the apex angle $\alpha$, the droplet sizes could be varied from $36 \mu \mathrm{m}$ to $446 \mu \mathrm{m}$ [178]. The authors exploited the ease of fabrication in P $\mu$ SL printing to fabricate four parallelized chimney-like microchannels for simultaneous droplet formation. Their approach has potential for widespread industrial use because of the excellent material uniformity and the high flow rates (as high as $70 \mathrm{~mL} \mathrm{~min}^{-1}$ ) with no device leakage. In 2015, Femmer et al. reported the preparation of parallelized microfluidic droplet makers with flow-focusing geometry for the high-throughput production of emulsions via P $\mu$ SL [179]. Their device comprised 28 parallelized droplet makers and produced $500 \mu \mathrm{m}$-diameter emulsion droplets at a rate of $3 \mathrm{~L} \mathrm{~h}^{-1}$; the droplets were transformed into microgels by a photochemical crosslinking reaction. 

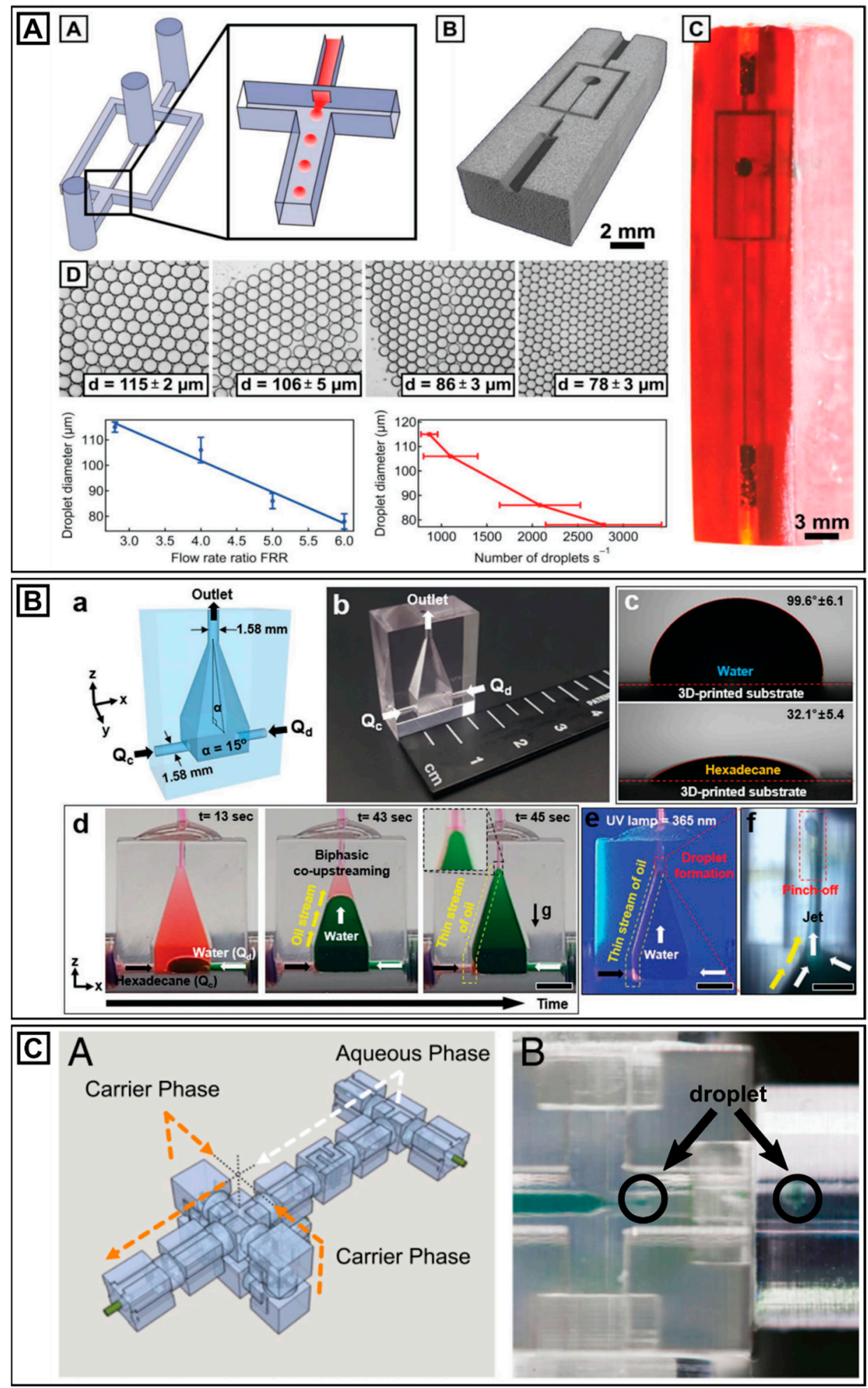

Figure 4. Microfluidic devices for emulsion formation, fabricated via P $\mu S L$. (A) Nonplanar flowfocusing device for forming both oil-in-water and water-in-oil emulsions. Droplet size is manipulated by adjusting the flow rate ratio (FRR). Adapted with permission from Thiele et al. [20] (B) 3Dprinted chimney-shaped millifluidic device for producing emulsions with diameters as small as 60 $\mu \mathrm{m}$. Adapted with permission from Kim et al. [177] (C) Interconnected discrete 3D-printed moduli, resulting in a flow-focusing device for microdroplet formation. Adapted with permission from Malmstadt et al. [81]. 
The common limitation of the aforementioned examples is that the microfluidic modules are fabricated as monoliths. The flow cell design needs to be adapted to implement additional microfluidic modules (e.g., a second consecutive junction or a valve), which usually requires additional printing steps. To address this problem, Malmstadt and coworkers developed a library of standardized components and connectors to assemble truly complex microfluidic systems in three dimensions (Figure 4C) [81]. The authors stated that their approach is superior to traditional methods with respect to cost and maintenance. The discrete elements are reversibly connected in a manner that is similar to LEGO ${ }^{\mathrm{TM}}$ bricks. To benchmark their concept, the authors first fabricated a T-junction device for forming droplets with a microchannel cross-section of $750 \mu \mathrm{m}$, where the connectors between fluidic elements were $1000 \mu \mathrm{m}$. By implementing four-way liquid processing, they also parallelized droplet formation, which indicated that their approach is not limited to 2D module assemblies. Eventually, by replacing the T-junction element with a cross-junction module, they assembled a flow-focusing device operating with a continuous-phase flow rate of $5 \mathrm{~mL} \mathrm{~h}^{-1}$ for forming water-in-oil emulsions.

Seo et al. [180] reported another example of a microfluidic device. They developed a drop maker that consists of two main components: an internal thread (nut) with a vertical T-junction and an external thread (screw). When rotated, the screw moved upward or downward, adjusting a gap at the T-junction, which enabled the droplet size to be varied from $39 \mu \mathrm{m}$ to over $1000 \mu \mathrm{m}$ within the same flow cell. Similar to the device proposed by Hwang et al. [177], that of Seo et al. [180] enabled the size of the droplets to be adjusted by more than two orders of magnitude without changing the CAD of the device.

\subsubsection{Double Emulsion Formation}

In recent years, not only simple single emulsions, but also microfluidically prepared double emulsions, which are droplets inside droplets, have attracted widespread interest, because the number of liquid cores as well as the core and shell volume can be well controlled [6]. Double emulsions have been used as templates for capsule and vesicle formation and they play a key role in drug delivery [3,181,182], food applications [4,183], and separation processes [184]. The production of microfluidic devices for forming double emulsions has been challenging because of the need for spatially controlled microchannel surface wettability. Although several approaches for overcoming the necessity of microchannel wettability patterning have been reported, they require extensive experience on the part of the user [185-187]. Here, 3D printing offers a facile route to circumvent this challenge, and eventually yields easy-to-fabricate devices for double emulsion formation. As described, changing the channel structure from a planar to a nonplanar 3D architecture results in negligible surface wettability, because the inner phase for droplet formation is fully surrounded by the outer phase. Zhang et al. reported a 3D-printed nonplanar, monolithic device with two consecutive flow-focusing junctions for forming both water-in-oil-in-water and oil-in-water-in-oil double emulsions (Figure 5A) [176]. Their device contained circular channels with diameters ranging from $600 \mu \mathrm{m}$ (inner phase) to $1000 \mu \mathrm{m}$ (middle phase) and $2000 \mu \mathrm{m}$ (outer phase). By forming both types of double emulsions in the same device, they demonstrated the convenience of 3D printing as compared to conventional fabrication methods, where different microfluidic devices are often used for different types of emulsions. Inspired by this approach, Männel et al. developed monolithic double emulsion devices with improved microchannel resolution. Their flow cells contained rectangular microchannels with cross sections of $100 \mu \mathrm{m}$ (inner phase) and $300 \mu \mathrm{m}$ (middle and outer phases) [20]. They also demonstrated that both types of double emulsions could be generated, and tuned the flow rates to encapsulate either one or two smaller droplets in the outer double emulsion droplet. 

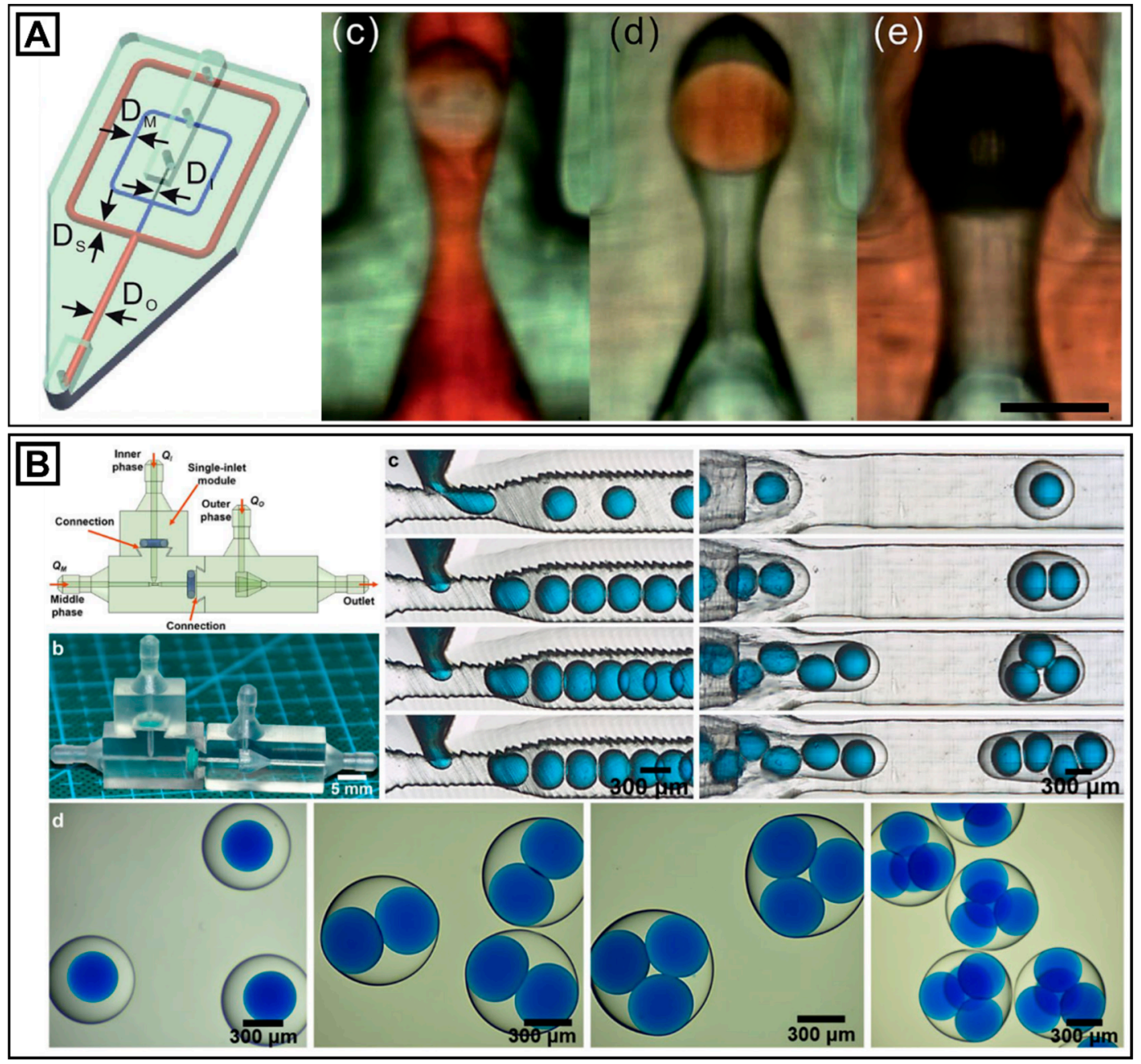

Figure 5. 3D-printed microfluidic devices for forming double emulsions. (A) Nonplanar microfluidic device design for producing oil-in-water-in-oil, water-in-oil-in-water, or air-in-oil-in-water emulsions. Adapted with permission from Thoroddsen et al. [176] (B) Device for forming double emulsions, assembled from 3D-printed flow cell modules. The number of encapsulated liquid cores could be tuned by adjusting the flow rates. Adapted with permission from Duan et al. [80].

In 2018, Takeuchi's group published the assembly of a coaxial microfluidic device for forming single and double emulsions [188]. Their modules were assembled via screw threads, and they could be easily rinsed after use. By assembling an axisymmetric flowfocusing device, they generated water-in-oil-in-water double emulsions with a diameter of $370 \mu \mathrm{m}$ for the outer droplet and $250 \mu \mathrm{m}$ for the inner droplet at flow rates of $10 \mu \mathrm{L}$

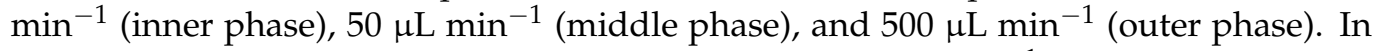
addition, by decreasing the outer phase's flow rate to $200 \mu \mathrm{L} \mathrm{min}^{-1}$, multiple inner water droplets with an average diameter of $234 \mu \mathrm{m}$ were encapsulated in the outer droplet with an average diameter of $835 \mu \mathrm{m}$. Ji et al. proposed another modular microfluidic device using multimaterial 3D printing [80]. They used two different 3D printers-a PolyJet and a Form-2 - for device fabrication. With the first printer, they 3D-printed an elastic pneumatic control unit; with the Form-2 printer, they 3D-printed microfluidic modules, such as Tjunctions. The different parts were connected via a notch structure, and an O-ring between the modules prevented device leakage. By connecting the pneumatic control unit with the T-junction module and the co-flow structure module, the authors formulated water-inoil-in-water double emulsions (Figure 5B). Before generating the actual double emulsions, the T-junction module's surface was rendered hydrophobic and the surface of the co-flow channel was rendered hydrophilic. Finally, the authors demonstrated full control over the number of encapsulated inner droplets from one to four encapsulated compartments. 


\section{Conclusions}

In this review, we presented an overview of the state of the art in microfluidic device fabrication via $\mathrm{P} \mu \mathrm{SL}$, focusing on droplet formation as the target application. Although the devices can be fabricated as monolithic or modular, each approach has advantages and disadvantages that must be considered. We hope that this overview helps researchers that are interested in this field in their decision-making process for identifying the most suitable approach for their studies. While we evaluate that $\mathrm{P} \mu \mathrm{SL}$ printers and resins in the market have reached a state where they will be able to revolutionize the fabrication of microfluidic devices, they suffer from inherent limitations, like poor transparency or processability. Thus, custom-made solutions on both the process side and the materials side are desired for full control over essential printing and material parameters, such as the minimum feature size, transparency, elasticity, and biocompatibility. In addition, the applications of microfluidic devices are so diverse that multimaterial printing using P $\mu \mathrm{SL}$ is an important focus of research for achieving different material and surface properties within flow cells. Because multimaterial printing is still in its early stages, additional studies for improving the system design, resolution, and material range are needed.

Author Contributions: M.J.M. and E.B. wrote the original draft of the manuscript and performed the literature research. All authors reviewed and edited the final manuscript. J.T. supervised the project and literature search, and proof-read the manuscript. All authors have read and agreed to the published version of the manuscript.

Funding: The authors' work on additive manufacturing has received funding from the European Research Council (ERC) under the European Union's Horizon 2020 research and innovation program (grant agreement No. 852065 3DPartForm), the Federal Ministry of Education and Research (BMBF, Biotechnology2020+: Leibniz Research Cluster, 031A360C), and the German Research Foundation (Research Training Group 1865 "Hydrogel-based microsystems").

Institutional Review Board Statement: Not applicable.

Informed Consent Statement: Not applicable.

Acknowledgments: J.T. acknowledges the Young Investigator Program of TU Dresden.

Conflicts of Interest: The authors declare no conflict of interest.

\section{References}

1. Whitesides, G.M. The origins and the future of microfluidics. Nature 2006, 442, 368-373. [CrossRef] [PubMed]

2. Nisisako, T.; Torii, T.; Higuchi, T. Novel microreactors for functional polymer beads. Chem. Eng. J. 2004, 101, 23-29. [CrossRef]

3. Zhang, Y.; Chan, H.F.; Leong, K.W. Advanced materials and processing for drug delivery: The past and the future. Adv. Drug Deliv. Rev. 2013, 65, 104-120. [CrossRef] [PubMed]

4. Muschiolik, G. Multiple emulsions for food use. Curr. Opin. Colloid Interface Sci. 2007, 12, 213-220. [CrossRef]

5. McDonald, J.C.; Whitesides, G.M. Poly(dimethylsiloxane) as a Material for Fabricating Microfluidic Devices. Accounts Chem. Res. 2002, 35, 491-499. [CrossRef]

6. Utada, A.S.; Lorenceau, E.; Link, D.R.; Kaplan, P.D.; Stone, H.A.; Weitz, D.A. Monodisperse Double Emulsions Generated from a Microcapillary Device. Science 2005, 308, 537-541. [CrossRef]

7. Martynova, L.; Locascio, L.E.; Gaitan, M.; Kramer, G.W.; Christensen, R.G.; MacCrehan, W.A. Fabrication of Plastic Microfluid Channels by Imprinting Methods. Anal. Chem. 1997, 69, 4783-4789. [CrossRef]

8. Becker, H.; Gärtner, C. Polymer microfabrication methods for microfluidic analytical applications. Electrophoresis 2000, 21, 12-26. [CrossRef]

9. McCormick, R.M.; Nelson, R.J.; Alonso-Amigo, M.G.; Benvegnu, D.J.; Hooper, H.H. Microchannel Electrophoretic Separations of DNA in Injection-Molded Plastic Substrates. Anal. Chem. 1997, 69, 2626-2630. [CrossRef]

10. Ng, S.H.; Wang, Z.F. Hot roller embossing for microfluidics: Process and challenges. Microsyst. Technol. 2009, 15, 1149-1156. [CrossRef]

11. Sollier, E.; Murray, C.; Maoddi, P.; Di Carlo, D. Rapid prototyping polymers for microfluidic devices and high pressure injections. Lab Chip 2011, 11, 3752-3765. [CrossRef]

12. Ortigoza-Diaz, J.; Scholten, K.; Larson, C.; Cobo, A.; Hudson, T.; Yoo, J.; Baldwin, A.; Hirschberg, A.W.; Meng, E. Techniques and Considerations in the Microfabrication of Parylene C Microelectromechanical Systems. Micromachines 2018, 9, 422. [CrossRef]

13. Zhang, J.M.; Ji, Q.; Duan, H. Three-Dimensional Printed Devices in Droplet Microfluidics. Micromachines 2019, 10, 754. [CrossRef] 
14. Yazdi, A.A.; Popma, A.; Wong, W.; Nguyen, T.; Pan, Y.; Xu, J. 3D printing: An emerging tool for novel microfluidics and lab-on-a-chip applications. Microfluid. Nanofluid. 2016, 20,1-18. [CrossRef]

15. Nielsen, A.V.; Beauchamp, M.J.; Nordin, G.P.; Woolley, A.T. 3D Printed Microfluidics. Annu. Rev. Anal. Chem. 2020, 13, 45-65. [CrossRef]

16. Nelson, M.D.; Ramkumar, N.; Gale, B.K. Flexible, transparent, sub-100 $\mu \mathrm{m}$ microfluidic channels with fused deposition modeling 3D-printed thermoplastic polyurethane. J. Micromech. Microeng. 2019, 29, 095010. [CrossRef]

17. Shen, W.; Li, M.; Ye, C.; Jiang, L.; Song, Y. Direct-writing colloidal photonic crystal microfluidic chips by inkjet printing for label-free protein detection. Lab Chip 2012, 12, 3089. [CrossRef]

18. Donvito, L.; Galluccio, L.; Lombardo, A.; Morabito, G.; Nicolosi, A.; Reno, M. Experimental validation of a simple, low-cost, T-junction droplet generator fabricated through 3D printing. J. Micromech. Microeng. 2015, 25, 035013. [CrossRef]

19. Wu, D.; Chen, Q.-D.; Niu, L.-G.; Wang, J.-N.; Wang, J.; Wang, R.; Xia, H.; Sun, H.-B. Femtosecond laser rapid prototyping of nanoshells and suspending components towards microfluidic devices. Lab Chip 2009, 9, 2391-2394. [CrossRef]

20. Männel, M.J.; Selzer, L.; Bernhardt, R.; Thiele, J. Optimizing Process Parameters in Commercial Micro-Stereolithography for Forming Emulsions and Polymer Microparticles in Nonplanar Microfluidic Devices. Adv. Mater. Technol. 2019, 4, 1800408. [CrossRef]

21. He, Y.; Wu, Y.; Fu, J.-Z.; Gao, Q.; Qiu, J.-J. Developments of 3D Printing Microfluidics and Applications in Chemistry and Biology: A Review. Electroanalysis 2016, 28, 1658-1678. [CrossRef]

22. Stampfl, J.; Liska, R.; Ovsianikov, A. Multiphoton Lithography: Techniques, Materials, and Applications; John Wiley \& Sons: Hoboken, NJ, USA, 2016.

23. Fischer, J.; Mueller, J.B.; Kaschke, J.; Wolf, T.J.A.; Unterreiner, A.-N.; Wegener, M. Three-dimensional multi-photon direct laser writing with variable repetition rate. Opt. Express 2013, 21, 26244-26260. [CrossRef] [PubMed]

24. LaFratta, C.N.; Baldacchini, T. Two-Photon Polymerization Metrology: Characterization Methods of Mechanisms and Microstructures. Micromachines 2017, 8, 101. [CrossRef]

25. Nguyen, A.K.; Narayan, R.J. Two-photon polymerization for biological applications. Mater. Today 2017, 20, 314-322. [CrossRef]

26. Solomon, I.J.; Sevvel, P.; Gunasekaran, J. A review on the various processing parameters in FDM. Mater. Today Proc. 2021, 37, 509-514. [CrossRef]

27. Macdonald, N.P.; Cabot, J.M.; Smejkal, P.; Guijt, R.M.; Paull, B.; Breadmore, M.C. Comparing Microfluidic Performance of Three-Dimensional (3D) Printing Platforms. Anal. Chem. 2017, 89, 3858-3866. [CrossRef]

28. Swetham, T.; Reddy, K.M.M.; Huggi, A. A Critical Review on of 3D Printing Materials and Details of Materials used in FDM. Int J. Sci. Res. Sci. Eng. 2017, 3, 353-361.

29. Gladman, A.S.; Matsumoto, E.A.; Nuzzo, R.G.; Mahadevan, L.; Lewis, J.A. Biomimetic 4D printing. Nat. Mater. 2016, 15, 413-418. [CrossRef]

30. Gosselin, C.; Duballet, R.; Roux, P.; Gaudillière, N.; Dirrenberger, J.; Morel, P. Large-scale 3D printing of ultra-high performance concrete-A new processing route for architects and builders. Mater. Des. 2016, 100, 102-109. [CrossRef]

31. Skylar-Scott, M.A.; Mueller, J.; Visser, C.W.; Lewis, J.A. Voxelated soft matter via multimaterial multinozzle 3D printing. Nature 2019, 575, 330-335. [CrossRef]

32. Lu, W.-E.; Dong, X.-Z.; Chen, W.-Q.; Zhao, Z.-S.; Duan, X.-M. Novel photoinitiator with a radical quenching moiety for confining radical diffusion in two-photon induced photopolymerization. J. Mater. Chem. 2011, 21, 5650-5659. [CrossRef]

33. Kawata, S.; Sun, H.-B.; Tanaka, T.; Takada, K. Finer features for functional microdevices. Nature 2001, 412, 697-698. [CrossRef]

34. Saha, S.K.; Wang, D.; Nguyen, V.H.; Chang, Y.; Oakdale, J.S.; Chen, S.-C. Scalable submicrometer additive manufacturing. Science 2019, 366, 105-109. [CrossRef]

35. Sun, C.; Fang, N.; Wu, D.; Zhang, X. Projection micro-stereolithography using digital micro-mirror dynamic mask. Sens. Actuators A Phys. 2005, 121, 113-120. [CrossRef]

36. Chen, X.; Liu, W.; Dong, B.; Lee, J.; Ware, H.O.T.; Zhang, H.F.; Sun, C. High-Speed 3D Printing of Millimeter-Size Customized Aspheric Imaging Lenses with Sub 7 nm Surface Roughness. Adv. Mater. 2018, 30, e1705683. [CrossRef]

37. Tumbleston, J.R.; Shirvanyants, D.; Ermoshkin, N.; Janusziewicz, R.; Johnson, A.R.; Kelly, D.; Chen, K.; Pinschmidt, R.; Rolland, J.P.; Ermoshkin, A.; et al. Continuous liquid interface production of 3D objects. Science 2015, 347, 1349-1352. [CrossRef]

38. Han, D.; Yang, C.; Fang, N.X.; Lee, H. Rapid multi-material 3D printing with projection micro-stereolithography using dynamic fluidic control. Addit. Manuf. 2019, 27, 606-615. [CrossRef]

39. Rahim, T.N.A.T.; Abdullah, A.M.; Akil, H.M. Recent Developments in Fused Deposition Modeling-Based 3D Printing of Polymers and Their Composites. Polym. Rev. 2019, 59, 589-624. [CrossRef]

40. Pinargote, N.W.S.; Smirnov, A.; Peretyagin, N.; Seleznev, A.; Peretyagin, P. Direct Ink Writing Technology (3D Printing) of Graphene-Based Ceramic Nanocomposites: A Review. Nanomaterials 2020, 10, 1300. [CrossRef]

41. Han, T.; Kundu, S.; Nag, A.; Xu, Y. 3D Printed Sensors for Biomedical Applications: A Review. Sensors 2019, 19, 1706. [CrossRef]

42. Lin, Y.; Xu, J. Microstructures Fabricated by Two-Photon Polymerization and Their Remote Manipulation Techniques: Toward 3D Printing of Micromachines. Adv. Opt. Mater. 2018, 6. [CrossRef]

43. Wang, Z.; Martin, N.; Hini, D.; Mills, B.; Kim, K. Rapid Fabrication of Multilayer Microfluidic Devices Using the Liquid Crystal Display-Based Stereolithography 3D Printing System. 3D Print. Addit. Manuf. 2017, 4, 156-164. [CrossRef] 
44. Lu, Y.; Mapili, G.; Suhali, G.; Chen, S.; Roy, K. A digital micro-mirror device-based system for the microfabrication of complex, spatially patterned tissue engineering scaffolds. J. Biomed. Mater. Res. Part A 2006, 77, 396-405. [CrossRef] [PubMed]

45. Zheng, X.; DeOtte, J.; Alonso, M.P.; Farquar, G.R.; Weisgraber, T.H.; Gemberling, S.; Lee, H.; Fang, N.; Spadaccini, C.M. Design and optimization of a light-emitting diode projection micro-stereolithography three-dimensional manufacturing system. Rev. Sci. Instrum. 2012, 83, 125001. [CrossRef]

46. Vaezi, M.; Seitz, H.; Yang, S. A review on 3D micro-additive manufacturing technologies. Int. J. Adv. Manuf. Technol. 2013, 67, 1721-1754. [CrossRef]

47. Ge, Q.; Li, Z.; Wang, Z.; Kowsari, K.; Zhang, W.; He, X.; Zhou, J.; Fang, N.X. Projection micro stereolithography based 3D printing and its applications. Int. J. Extreme Manuf. 2020, 2, 022004. [CrossRef]

48. Sochol, R.D.; Sweet, E.; Glick, C.C.; Wu, S.-Y.; Yang, C.; Restaino, M.; Lin, L. 3D printed microfluidics and microelectronics. Microelectron. Eng. 2018, 189, 52-68. [CrossRef]

49. Huang, B.; Hu, R.; Xue, Z.; Zhao, J.; Li, Q.; Xia, T.; Zhang, W.; Lu, C. Continuous liquid interface production of alginate/polyacrylamide hydrogels with supramolecular shape memory properties. Carbohydr. Polym. 2020, 231, 115736. [CrossRef]

50. Ware, H.O.T.; Farsheed, A.C.; Akar, B.; Duan, C.; Chen, X.; Ameer, G.; Sun, C. High-speed on-demand 3D printed bioresorbable vascular scaffolds. Mater. Today Chem. 2018, 7, 25-34. [CrossRef]

51. Johnson, A.R.; Caudill, C.L.; Tumbleston, J.R.; Bloomquist, C.J.; Moga, K.A.; Ermoshkin, A.; Shirvanyants, D.; Mecham, S.J.; Luft, J.C.; DeSimone, J.M. Single-Step Fabrication of Computationally Designed Microneedles by Continuous Liquid Interface Production. PLoS ONE 2016, 11, e0162518. [CrossRef]

52. He, H.; Yang, Y.; Pan, Y. Machine learning for continuous liquid interface production: Printing speed modelling. J. Manuf. Syst. 2019, 50, 236-246. [CrossRef]

53. Kelly, B.E.; Bhattacharya, I.; Heidari, H.; Shusteff, M.; Spadaccini, C.M.; Taylor, H.K. Volumetric additive manufacturing via tomographic reconstruction. Science 2019, 363, 1075-1079. [CrossRef]

54. Lamont, A.C.; Alsharhan, A.T.; Sochol, R.D. Geometric Determinants of In-Situ Direct Laser Writing. Sci. Rep. 2019, 9, 1-12. [CrossRef]

55. Regehly, M.; Garmshausen, Y.; Reuter, M.; König, N.F.; Israel, E.; Kelly, D.P.; Chou, C.-Y.; Koch, K.; Asfari, B.; Hecht, S. Xolography for linear volumetric 3D printing. Nat. Cell Biol. 2020, 588, 620-624. [CrossRef]

56. Alsharhan, A.T.; Acevedo, R.; Warren, R.; Sochol, R.D. 3D microfluidics via cyclic olefin polymer-based in situ direct laser writing. Lab Chip 2019, 19, 2799-2810. [CrossRef]

57. Bückmann, T.; Stenger, N.; Kadic, M.; Kaschke, J.; Frölich, A.; Kennerknecht, T.; Eberl, C.; Thiel, M.; Wegener, M. Tailored 3D Mechanical Metamaterials Made by Dip-in Direct-Laser-Writing Optical Lithography. Adv. Mater. 2012, 24, 2710-2714. [CrossRef]

58. Di Giacomo, R.; Krödel, S.; Maresca, B.; Benzoni, P.; Rusconi, R.; Stocker, R.; Daraio, C. Deployable micro-traps to sequester motile bacteria. Sci. Rep. 2017, 7, srep45897. [CrossRef]

59. Son, A.I.; Opfermann, J.D.; McCue, C.; Ziobro, J.; Abrahams, J.H.; Jones, K.; Morton, P.D.; Ishii, S.; Oluigbo, C.; Krieger, A.; et al. An Implantable Micro-Caged Device for Direct Local Delivery of Agents. Sci. Rep. 2017, 7, 1-16. [CrossRef]

60. Perrucci, F.; Bertana, V.; Marasso, S.; Scordo, G.; Ferrero, S.; Pirri, C.; Cocuzza, M.; El-Tamer, A.; Hinze, U.; Chichkov, B.; et al. Optimization of a suspended two photon polymerized microfluidic filtration system. Microelectron. Eng. 2018, 195, 95-100. [CrossRef]

61. Mayer, F.; Richter, S.; Westhauser, J.; Blasco, E.; Barner-Kowollik, C.; Wegener, M. Multimaterial 3D laser microprinting using an integrated microfluidic system. Sci. Adv. 2019, 5, eaau9160. [CrossRef]

62. Nishiguchi, D.; Aranson, I.S.; Snezhko, A.; Sokolov, A. Engineering bacterial vortex lattice via direct laser lithography. Nat. Commun. 2018, 9, 4486. [CrossRef] [PubMed]

63. Hippler, M.; Blasco, E.; Qu, J.; Tanaka, M.; Barner-Kowollik, C.; Wegener, M.; Bastmeyer, M. Controlling the shape of 3D microstructures by temperature and light. Nat. Commun. 2019, 10, 1-8. [CrossRef] [PubMed]

64. Amato, L.; Gu, Y.; Bellini, N.; Eaton, S.M.; Cerullo, G.; Osellame, R. Integrated three-dimensional filter separates nanoscale from microscale elements in a microfluidic chip. Lab Chip 2012, 12, 1135-1142. [CrossRef] [PubMed]

65. Zhang, B.; Gao, L.; Xue, Q.; Cui, Z.; Ma, L.; Yang, H. Strengths, weaknesses, and applications of computational axial lithography in tissue engineering. Bio Design Manuf. 2020, 3, 5-6. [CrossRef]

66. Bernal, P.N.; Delrot, P.; Loterie, D.; Li, Y.; Malda, J.; Moser, C.; Levato, R. Volumetric Bioprinting of Complex Living-Tissue Constructs within Seconds. Adv. Mater. 2019, 31, e1904209. [CrossRef]

67. Loterie, D.; Delrot, P.; Moser, C. High-resolution tomographic volumetric additive manufacturing. Nat. Commun. 2020, 11, 1-6. [CrossRef]

68. Gong, H.; Bickham, B.P.; Woolley, A.T.; Nordin, G.P. Custom 3D printer and resin for $18 \mu \mathrm{m} \times 20 \mu \mathrm{m}$ microfluidic flow channels. Lab Chip 2017, 17, 2899-2909. [CrossRef]

69. Behroodi, E.; Latifi, H.; Najafi, F. A compact LED-based projection microstereolithography for producing 3D microstructures. Sci. Rep. 2019, 9, 1-14. [CrossRef]

70. Bartlett, N.W.; Tolley, M.T.; Overvelde, J.T.B.; Weaver, J.C.; Mosadegh, B.; Bertoldi, K.; Whitesides, G.M.; Wood, R.J. A 3D-printed, functionally graded soft robot powered by combustion. Science 2015, 349, 161-165. [CrossRef]

71. Kuang, X.; Chen, K.; Dunn, C.K.; Wu, J.; Li, V.C.F.; Qi, H.J. 3D Printing of Highly Stretchable, Shape-Memory, and Self-Healing Elastomer toward Novel 4D Printing. ACS Appl. Mater. Interfaces 2018, 10, 7381-7388. [CrossRef] 
72. Patel, D.K.; Sakhaei, A.H.; Layani, M.; Zhang, B.; Ge, Q.; Magdassi, S. Highly Stretchable and UV Curable Elastomers for Digital Light Processing Based 3D Printing. Adv. Mater. 2017, 29, 1606000. [CrossRef]

73. Thrasher, C.J.; Schwartz, J.J.; Boydston, A.J. Modular Elastomer Photoresins for Digital Light Processing Additive Manufacturing. ACS Appl. Mater. Interfaces 2017, 9, 39708-39716. [CrossRef]

74. Zhou, J.; Khodakov, D.A.; Ellis, A.V.; Voelcker, N.H. Surface modification for PDMS-based microfluidic devices. Electrophoresis 2011, 33, 89-104. [CrossRef]

75. Kolesky, D.B.; Truby, R.L.; Gladman, A.S.; Busbee, T.A.; Homan, K.A.; Lewis, J.A. 3D Bioprinting of Vascularized, Heterogeneous Cell-Laden Tissue Constructs. Adv. Mater. 2014, 26, 3124-3130. [CrossRef]

76. Espalin, D.; Ramirez, J.A.; Medina, F.; Wicker, R.B. Multi-material, multi-technology FDM: Exploring build process variations. Rapid Prototyp. J. 2014, 20, 236-244. [CrossRef]

77. Wang, K.; Wu, C.; Qian, Z.; Zhang, C.; Wang, B.; Vannan, M.A. Dual-material 3D printed metamaterials with tunable mechanical properties for patient-specific tissue-mimicking phantoms. Addit. Manuf. 2016, 12, 31-37. [CrossRef]

78. Choi, J.-W.; Kim, H.-C.; Wicker, R. Multi-material stereolithography. J. Mater. Process. Technol. 2011, 211, 318-328. [CrossRef]

79. Kowsari, K.; Akbari, S.; Wang, D.; Fang, N.X.; Ge, Q. High-Efficiency High-Resolution Multimaterial Fabrication for Digital Light Processing-Based Three-Dimensional Printing. 3D Print. Addit. Manuf. 2018, 5, 185-193. [CrossRef]

80. Ji, Q.; Zhang, J.M.; Liu, Y.; Li, X.; Lv, P.; Jin, D.; Duan, H. A Modular Microfluidic Device via Multimaterial 3D Printing for Emulsion Generation. Sci. Rep. 2018, 8, 1-11. [CrossRef]

81. Bhargava, K.C.; Thompson, B.; Malmstadt, N. Discrete elements for 3D microfluidics. Proc. Natl. Acad. Sci. USA 2014, 111, 15013-15018. [CrossRef]

82. Ching, T.; Toh, Y.-C.; Hashimoto, M. Fabrication of Complex 3D Fluidic Networks via Modularized Stereolithography. Adv. Eng. Mater. 2020, 22, 1901109. [CrossRef]

83. Lee, J.-Y.; An, J.; Chua, C.K. Fundamentals and applications of 3D printing for novel materials. Appl. Mater. Today 2017, 7, 120-133. [CrossRef]

84. Khoo, Z.X.; Teoh, J.E.M.; Liu, Y.; Chua, C.K.; Yang, S.; An, J.; Leong, K.F.; Yeong, W.Y. 3D printing of smart materials: A review on recent progresses in 4D printing. Virtual Phys. Prototyp. 2015, 10, 103-122. [CrossRef]

85. Kuang, X.; Roach, D.J.; Wu, J.; Hamel, C.M.; Ding, Z.; Wang, T.; Dunn, M.L.; Qi, H.J. Advances in 4D Printing: Materials and Applications. Adv. Funct. Mater. 2019, 29, 1805290. [CrossRef]

86. Choi, J.; Kwon, O.-C.; Jo, W.; Lee, H.J.; Moon, M.-W. 4D Printing Technology: A Review. 3D Print. Addit. Manuf. 2015, 2, 159-167. [CrossRef]

87. Shie, M.-Y.; Shen, Y.-F.; Astuti, S.D.; Lee, A.K.-X.; Lin, S.-H.; Dwijaksara, N.L.B.; Chen, Y.-W. Review of Polymeric Materials in 4D Printing Biomedical Applications. Polymers 2019, 11, 1864. [CrossRef] [PubMed]

88. Hoffman, A.S. Stimuli-responsive polymers: Biomedical applications and challenges for clinical translation. Adv. Drug Deliv. Rev. 2013, 65, 10-16. [CrossRef] [PubMed]

89. Bakarich, S.E.; Gorkin III, R.; Panhuis, M.I.H.; Spinks, G.M. 4D Printing with Mechanically Robust, Thermally Actuating Hydrogels. Macromol. Rapid Commun. 2015, 36, 1211-1217. [CrossRef] [PubMed]

90. Leong, T.G.; Randall, C.L.; Benson, B.R.; Bassik, N.; Stern, G.M.; Gracias, D.H. Tetherless thermobiochemically actuated microgrippers. Proc. Natl. Acad. Sci. USA 2009, 106, 703-708. [CrossRef] [PubMed]

91. Firth, J.; Gaisford, S.; Basit, A.W. A New Dimension: 4D Printing Opportunities in Pharmaceutics. In 3D Printing of Pharmaceuticals; Basit, A.W., Gaisford, S., Eds.; Springer International Publishing: Cham, Switzerland, 2018; pp. 153-162.

92. Seiffert, S.; Thiele, J.; Abate, A.R.; Weitz, D.A. Smart Microgel Capsules from Macromolecular Precursors. J. Am. Chem. Soc. 2010, 132, 6606-6609. [CrossRef] [PubMed]

93. Bajpai, A.; Baigent, A.; Raghav, S.; Brádaigh, C.; Koutsos, V.; Radacsi, N. 4D Printing: Materials, Technologies, and Future Applications in the Biomedical Field. Sustainability 2020, 12, 10628. [CrossRef]

94. Ruskowitz, E.R.; Deforest, C.A. Photoresponsive biomaterials for targeted drug delivery and 4D cell culture. Nat. Rev. Mater. 2018, 3, 17087. [CrossRef]

95. Doberenz, F.; Zeng, K.; Willems, C.; Zhang, K.; Groth, T. Thermoresponsive polymers and their biomedical application in tissue engineering-A review. J. Mater. Chem. B 2020, 8, 607-628. [CrossRef]

96. Joyee, E.B.; Pan, Y. A Fully Three-Dimensional Printed Inchworm-Inspired Soft Robot with Magnetic Actuation. Soft Robot. 2019, 6, 333-345. [CrossRef]

97. Javaid, M.; Haleem, A. 4D printing applications in medical field: A brief review. Clin. Epidemiol. Glob. Health 2019, 7, 317-321. [CrossRef]

98. Tamay, D.G.; Usal, T.D.; Alagoz, A.S.; Yucel, D.; Hasirci, N.; Hasirci, V. 3D and 4D Printing of Polymers for Tissue Engineering Applications. Front. Bioeng. Biotechnol. 2019, 7, 164. [CrossRef]

99. Lui, Y.S.; Sow, W.T.; Tan, L.P.; Wu, Y.; Lai, Y.; Li, H. 4D printing and stimuli-responsive materials in biomedical aspects. Acta Biomater. 2019, 92, 19-36. [CrossRef]

100. Zhang, Y.S.; Yue, K.; Aleman, J.; Mollazadeh-Moghaddam, K.; Bakht, S.M.; Yang, J.; Jia, W.; Dell'Erba, V.; Assawes, P.; Shin, S.R.; et al. 3D Bioprinting for Tissue and Organ Fabrication. Ann. Biomed. Eng. 2017, 45, 148-163. [CrossRef]

101. Jauffred, L.; Samadi, A.; Klingberg, H.; Bendix, P.M.; Oddershede, L.B. Plasmonic Heating of Nanostructures. Chem. Rev. 2019, 119, 8087-8130. [CrossRef] 
102. Dai, S.; Ravi, P.; Tam, K.C. pH-Responsive polymers: Synthesis, properties and applications. Soft Matter 2008, 4, 435-449. [CrossRef]

103. Zhang, Z.; Demir, K.G.; Gu, G.X. Developments in 4D-printing: A review on current smart materials, technologies, and applications. Int. J. Smart Nano Mater. 2019, 10, 205-224. [CrossRef]

104. Heskins, M.; Guillet, J.E. Solution Properties of Poly(N-isopropylacrylamide). J. Macromol. Sci. Part A Chem. 1968, 2, $1441-1455$. [CrossRef]

105. Quanjin, M.; Rejab, M.; Idris, M.; Kumar, N.M.; Abdullah, M.; Reddy, G.R. Recent 3D and 4D intelligent printing technologies: A comparative review and future perspective. Procedia Comput. Sci. 2020, 167, 1210-1219. [CrossRef]

106. Bhat, G.; Kandagor, V. 1-Synthetic polymer fibers and their processing requirements. In Advances in Filament Yarn Spinning of Textiles and Polymers; Zhang, D., Ed.; Woodhead Publishing: Sawston, UK, 2014; pp. 3-30.

107. Louie, B.M.; Carratt, G.M.; Soong, D.S. Modeling the free radical solution and bulk polymerization of methyl methacrylate. J. Appl. Polym. Sci. 1985, 30, 3985-4012. [CrossRef]

108. Jašo, V.; Stoiljković, D.; Radičević, R.; Bera, O. Kinetic modeling of bulk free-radical polymerization of methyl methacrylate. Polym. J. 2013, 45, 631-636. [CrossRef]

109. Rudin, A.; Choi, P. (Eds.) Chapter 12-Polymer Reaction Engineering. In The Elements of Polymer Science E Engineering, 3rd ed.; Academic Press: Boston, MA, USA, 2013; pp. 495-520.

110. Benjamin, A.D.; Abbasi, R.; Owens, M.; Olsen, R.J.; Walsh, D.J.; Lefevre, T.B.; Wilking, J.N. Light-based 3D printing of hydrogels with high-resolution channels. Biomed. Phys. Eng. Express 2018, 5, 025035. [CrossRef]

111. Stansbury, J.W.; Idacavage, M.J. 3D printing with polymers: Challenges among expanding options and opportunities. Dent. Mater. 2016, 32, 54-64. [CrossRef] [PubMed]

112. Knowlton, S.; Yenilmez, B.; Anand, S.; Tasoglu, S. Photocrosslinking-based bioprinting: Examining crosslinking schemes. Bioprinting 2017, 5, 10-18. [CrossRef]

113. Bagheri, A.; Jin, J. Photopolymerization in 3D Printing. ACS Appl. Polym. Mater. 2019, 1, 593-611. [CrossRef]

114. Waldbaur, A.; Rapp, H.; Länge, K.; Rapp, B.E. Let there be chip-towards rapid prototyping of microfluidic devices: One-step manufacturing processes. Anal. Methods 2011, 3, 2681-2716. [CrossRef]

115. Ligon, S.C.; Liska, R.; Stampfl, J.; Gurr, M.; Mülhaupt, R. Polymers for 3D Printing and Customized Additive Manufacturing. Chem. Rev. 2017, 117, 10212-10290. [CrossRef]

116. Xiang, H.; Wang, X.; Ou, Z.; Lin, G.; Yin, J.; Liu, Z.; Zhang, L.; Liu, X. UV-curable, 3D printable and biocompatible silicone elastomers. Prog. Org. Coat. 2019, 137, 105372. [CrossRef]

117. Wallin, T.J.; Pikul, J.H.; Bodkhe, S.; Peele, B.N.; Mac Murray, B.C.; Therriault, D.; McEnerney, B.W.; Dillon, R.P.; Giannelis, E.P.; Shepherd, R.F. Click chemistry stereolithography for soft robots that self-heal. J. Mater. Chem. B 2017, 5, 6249-6255. [CrossRef]

118. Liu, Z.; Hong, P.; Huang, Z.; Zhang, T.; Xu, R.; Chen, L.; Xiang, H.; Liu, X. Self-healing, reprocessing and 3D printing of transparent and hydrolysis-resistant silicone elastomers. Chem. Eng. J. 2020, 387, 124142. [CrossRef]

119. Oesterreicher, A.; Wiener, J.; Roth, M.; Moser, A.; Gmeiner, R.; Edler, M.; Pinter, G.; Griesser, T. Tough and degradable photopolymers derived from alkyne monomers for 3D printing of biomedical materials. Polym. Chem. 2016, 7, 5169-5180. [CrossRef]

120. Yu, K.; Xin, A.; Du, H.; Li, Y.; Wang, Q. Additive manufacturing of self-healing elastomers. NPG Asia Mater. 2019, 11, 7. [CrossRef]

121. Zieger, M.M.; Müller, P.; Blasco, E.; Petit, C.; Hahn, V.; Michalek, L.; Mutlu, H.; Wegener, M.; Barner-Kowollik, C. A Subtractive Photoresist Platform for Micro- and Macroscopic 3D Printed Structures. Adv. Funct. Mater. 2018, 28, 1801405. [CrossRef]

122. Zieger, M.M.; Mueller, P.; Quick, A.S.; Wegener, M.; Barner-Kowollik, C. Cleaving Direct-Laser-Written Microstructures on Demand. Angew. Chem. Int. Ed. 2017, 56, 5625-5629. [CrossRef]

123. Konuray, O.; Fernández-Francos, X.; De La Flor, S.; Ramis, X.; Serra, À. The Use of Click-Type Reactions in the Preparation of Thermosets. Polymers 2020, 12, 1084. [CrossRef]

124. Crivello, J.V.; Liu, S. Photoinitiated cationic polymerization of epoxy alcohol monomers. J. Polym. Sci. Part A Polym. Chem. 2000, 38, 389-401. [CrossRef]

125. Gernhardt, M.; Blasco, E.; Hippler, M.; Blinco, J.; Bastmeyer, M.; Wegener, M.; Frisch, H.; Barner-Kowollik, C. Tailoring the Mechanical Properties of 3D Microstructures Using Visible Light Post-Manufacturing. Adv. Mater. 2019, 31, e1901269. [CrossRef]

126. Houck, H.A.; Blasco, E.; Du Prez, F.E.; Barner-Kowollik, C. Light-Stabilized Dynamic Materials. J. Am. Chem. Soc. 2019, 141, 12329-12337. [CrossRef]

127. Bagheri, A.; Engel, K.E.; Bainbridge, C.W.A.; Xu, J.; Boyer, C.; Jin, J. 3D printing of polymeric materials based on photo-RAFT polymerization. Polym. Chem. 2020, 11, 641-647. [CrossRef]

128. Bainbridge, C.W.A.; Engel, K.E.; Jin, J. 3D printing and growth induced bending based on PET-RAFT polymerization. Polym. Chem. 2020, 11, 4084-4093. [CrossRef]

129. Crivello, J.V.; Lam, J.H.W. Photoinitiated cationic polymerization with triarylsulfonium salts. J. Polym. Sci. Part A Polym. Chem. 1996, 34, 3231-3253. [CrossRef]

130. Crivello, J.V.; Lam, J.H.W. Complex triarylsulfonium salt photoinitiators. I. The identification, characterization, and syntheses of a new class of triarylsulfonium salt photoinitiators. J. Polym. Sci. Polym. Chem. Ed. 1980, 18, 2677-2695. [CrossRef]

131. Lantean, S.; Roppolo, I.; Sangermano, M.; Pirri, C.F.; Chiappone, A. Development of New Hybrid Acrylic/Epoxy DLP-3D Printable Materials. Inventions 2018, 3, 29. [CrossRef] 
132. Zhao, T.; Yu, R.; Li, X.; Zhang, Y.; Yang, X.; Zhao, X.; Huang, W. A comparative study on 3D printed silicone-epoxy/acrylate hybrid polymers via pure photopolymerization and dual-curing mechanisms. J. Mater. Sci. 2019, 54, 5101-5111. [CrossRef]

133. Adzima, B.J.; Tao, Y.; Kloxin, C.J.; Deforest, C.A.; Anseth, K.S.; Bowman, C.N. Spatial and temporal control of the alkyne-azide cycloaddition by photoinitiated Cu(II) reduction. Nat. Chem. 2011, 3, 256-259. [CrossRef]

134. Petersen, S.R.; Wilson, J.A.; Becker, M.L. Versatile Ring-Opening Copolymerization and Postprinting Functionalization of Lactone and Poly(propylene fumarate) Block Copolymers: Resorbable Building Blocks for Additive Manufacturing. Macromolecules 2018, 51, 6202-6208. [CrossRef]

135. Pratama, P.A.; Sharifi, M.; Peterson, A.M.; Palmese, G.R. Room Temperature Self-Healing Thermoset Based on the Diels-Alder Reaction. ACS Appl. Mater. Interfaces 2013, 5, 12425-12431. [CrossRef]

136. Li, X.; Yu, R.; He, Y.; Zhang, Y.; Yang, X.; Zhao, X.; Huang, W. Four-dimensional printing of shape memory polyurethanes with high strength and recyclability based on Diels-Alder chemistry. Polymers 2020, 200, 122532. [CrossRef]

137. Houck, H.A.; Müller, P.; Wegener, M.; Barner-Kowollik, C.; Du Prez, F.E.; Blasco, E. Shining Light on Poly(ethylene glycol): From Polymer Modification to 3D Laser Printing of Water Erasable Microstructures. Adv. Mater. 2020, 32, e2003060. [CrossRef] [PubMed]

138. GhavamiNejad, A.; Ashammakhi, N.; Wu, X.Y.; Khademhosseini, A. Crosslinking Strategies for 3D Bioprinting of Polymeric Hydrogels. Small 2020, 16, 2002931. [CrossRef] [PubMed]

139. Rogers, C.I.; Qaderi, K.; Woolley, A.T.; Nordin, G.P. 3D printed microfluidic devices with integrated valves. Biomicrofluidics 2015, 9, 016501. [CrossRef] [PubMed]

140. Choi, J.-W.; Wicker, R.; Lee, S.-H.; Choi, K.-H.; Ha, C.-S.; Chung, I. Fabrication of 3D biocompatible/biodegradable micro-scaffolds using dynamic mask projection microstereolithography. J. Mater. Process. Technol. 2009, 209, 5494-5503. [CrossRef]

141. Kowsari, K.; Zhang, B.; Panjwani, S.; Chen, Z.; Hingorani, H.; Akbari, S.; Fang, N.X.; Ge, Q. Photopolymer formulation to minimize feature size, surface roughness, and stair-stepping in digital light processing-based three-dimensional printing. Addit. Manuf. 2018, 24, 627-638. [CrossRef]

142. Zarek, M.; Layani, M.; Cooperstein, I.; Sachyani, E.; Cohn, D.; Magdassi, S. 3D Printing of Shape Memory Polymers for Flexible Electronic Devices. Adv. Mater. 2016, 28, 4449-4454. [CrossRef]

143. Hada, T.; Kanazawa, M.; Iwaki, M.; Arakida, T.; Soeda, Y.; Katheng, A.; Otake, R.; Minakuchi, S. Effect of Printing Direction on the Accuracy of 3D-Printed Dentures Using Stereolithography Technology. Materials 2020, 13, 3405. [CrossRef]

144. Lipson, H.; Kurman, M. Fabricated: The New World of 3D Printing; John Wiley \& Sons: Hoboken, NJ, USA, 2013.

145. Gong, H.; Beauchamp, M.; Perry, S.T.; Woolley, A.T.; Nordin, G.P. Optical approach to resin formulation for 3D printed microfluidics. RSC Adv. 2015, 5, 106621-106632. [CrossRef]

146. Huang, B.; Du, Z.; Yong, T.; Han, W. Preparation of a novel hybrid type photosensitive resin for stereolithography in 3D printing and testing on the accuracy of the fabricated parts. J. Wuhan Univ. Technol. Sci. Ed. 2017, 32, 726-732. [CrossRef]

147. DruckWege GmbH. Available online: https://druckwege.de/high-temp-resin (accessed on 30 April 2021).

148. Männel, M.J.; Fischer, C.; Thiele, J. A Non-Cytotoxic Resin for Micro-Stereolithography for Cell Cultures of HUVECs. Micromachines 2020, 11, 246. [CrossRef]

149. Warr, C.; Valdoz, J.C.; Bickham, B.P.; Knight, C.J.; Franks, N.A.; Chartrand, N.; Van Ry, P.M.; Christensen, K.A.; Nordin, G.P.; Cook, A.D. Biocompatible PEGDA Resin for 3D Printing. ACS Appl. Bio Mater. 2020, 3, 2239-2244. [CrossRef]

150. Kotz, F.; Arnold, K.; Bauer, W.; Schild, D.; Keller, N.; Sachsenheimer, K.; Nargang, T.M.; Richter, C.; Helmer, D.; Rapp, B.E. Three-dimensional printing of transparent fused silica glass. Nature 2017, 544, 337-339. [CrossRef]

151. Peele, B.N.; Wallin, T.J.; Zhao, H.; Shepherd, R.F. 3D printing antagonistic systems of artificial muscle using projection stereolithography. Bioinspir. Biomim. 2015, 10, 055003. [CrossRef]

152. Oh, S.; Kim, B.; Lee, J.K.; Choi, S. 3D-printed capillary circuits for rapid, low-cost, portable analysis of blood viscosity. Sens. Actuators B Chem. 2018, 259, 106-113. [CrossRef]

153. Zhou, Z.; Kong, T.; Mkaouar, H.; Salama, K.N.; Zhang, J.M. A hybrid modular microfluidic device for emulsion generation. Sens. Actuators A Phys. 2018, 280, 422-428. [CrossRef]

154. Plevniak, K.; Campbell, M.; Myers, T.; Hodges, A.; He, M. 3D printed auto-mixing chip enables rapid smartphone diagnosis of anemia. Biomicrofluidics 2016, 10, 054113. [CrossRef]

155. Lee, J.M.; Zhang, M.; Yeong, W.Y. Characterization and evaluation of 3D printed microfluidic chip for cell processing. Microfluid. Nanofluid. 2016, 20,1-15. [CrossRef]

156. Shallan, A.I.; Smejkal, P.; Corban, M.; Guijt, R.M.; Breadmore, M.C. Cost-Effective Three-Dimensional Printing of Visibly Transparent Microchips within Minutes. Anal. Chem. 2014, 86, 3124-3130. [CrossRef]

157. Kuo, A.P.; Bhattacharjee, N.; Lee, Y.; Castro, K.; Kim, Y.T.; Folch, A. High-Precision Stereolithography of Biomicrofluidic Devices. Adv. Mater. Technol. 2019, 4. [CrossRef] [PubMed]

158. Loessberg-Zahl, J.; van der Meer, A.D.; van der Berg, A.; Eijkel, J.C.T. Flow focusing through gels as a tool to generate 3D concentration profiles in hydrogel-filled microfluidic chips. Lab Chip 2018, 19, 206-213. [CrossRef] [PubMed]

159. Zhang, J.M.; Aguirre-Pablo, A.A.; Li, E.Q.; Buttner, U.; Thoroddsen, S.T. Droplet generation in cross-flow for cost-effective 3D-printed "plug-and-play" microfluidic devices. RSC Adv. 2016, 6, 81120-81129. [CrossRef] 
160. Takenaga, S.; Schneider, B.H.; Erbay, E.; Biselli, M.; Schnitzler, T.; Schoning, M.J.; Wagner, T. Fabrication of biocompatible lab-on-chip devices for biomedical applications by means of a 3D-printing process. Phys. Status Solidi A 2015, 212, 1347-1352. [CrossRef]

161. Urrios, A.; Parra-Cabrera, C.; Bhattacharjee, N.; Gonzalez-Suarez, A.M.; Rigat-Brugarolas, L.G.; Nallapatti, U.; Samitier, J.; Deforest, C.A.; Posas, F.; Garcia-Cordero, J.L.; et al. 3D-printing of transparent bio-microfluidic devices in PEG-DA. Lab Chip 2016, 16, 2287-2294. [CrossRef]

162. Lee, W.; Kwon, D.; Choi, W.; Jung, G.Y.; Au, A.K.; Folch, A.; Jeon, S. Corrigendum: 3D-Printed Microfluidic Device for the Detection of Pathogenic Bacteria Using Size-based Separation in Helical Channel with Trapezoid Cross-Section. Sci. Rep. 2015, 5, 9701. [CrossRef]

163. Lee, W.; Kwon, D.; Chung, B.; Jung, G.Y.; Au, A.; Folch, A.; Jeon, S. Ultrarapid Detection of Pathogenic Bacteria Using a 3D Immunomagnetic Flow Assay. Anal. Chem. 2014, 86, 6683-6688. [CrossRef]

164. Alessandri, K.; Feyeux, M.; Gurchenkov, B.; Delgado, C.; Trushko, A.; Krause, K.-H.; Vignjević, D.; Nassoy, P.; Roux, A. A 3D printed microfluidic device for production of functionalized hydrogel microcapsules for culture and differentiation of human Neuronal Stem Cells (hNSC). Lab Chip 2016, 16, 1593-1604. [CrossRef]

165. Unger, M.A.; Chou, H.-P.; Thorsen, T.; Scherer, A.; Quake, S.R. Monolithic Microfabricated Valves and Pumps by Multilayer Soft Lithography. Science 2000, 288, 113-116. [CrossRef]

166. Au, A.K.; Bhattacharjee, N.; Horowitz, L.F.; Chang, T.C.; Folch, A. 3D-printed microfluidic automation. Lab Chip 2015, 15, 1934-1941. [CrossRef]

167. Lee, Y.-S.; Bhattacharjee, N.; Folch, A. 3D-printed Quake-style microvalves and micropumps. Lab Chip 2018, 18, 1207-1214. [CrossRef]

168. Armani, D.; Liu, C.; Aluru, N. Re-configurable fluid circuits by PDMS elastomer micromachining. In Technical Digest, Proceedings of the IEEE International MEMS 99 Conference, Twelfth IEEE International Conference on Micro Electro Mechanical Systems (Cat. No.99CH36291), Orlando, FL, USA, 21-21 January 1999; IEEE: Piscataway, NJ, USA, 1999; pp. 222-227.

169. Mannel, M.J.; Weigel, N.; Thiele, J. Multifunctional microfluidic devices from tailored photopolymer formulations. Microfluid. BioMEMS Med. Microsyst. XVII 2019, 10875. [CrossRef]

170. Rogers, C.I.; Oxborrow, J.B.; Anderson, R.R.; Tsai, L.-F.; Nordin, G.P.; Woolley, A.T. Microfluidic valves made from polymerized polyethylene glycol diacrylate. Sens. Actuators B Chem. 2014, 191, 438-444. [CrossRef]

171. Gong, H.; Woolley, A.T.; Nordin, G.P. High density 3D printed microfluidic valves, pumps, and multiplexers. Lab Chip 2016, 16, 2450-2458. [CrossRef]

172. Anna, S.L. Droplets and Bubbles in Microfluidic Devices. Annu. Rev. Fluid Mech. 2016, 48, 285-309. [CrossRef]

173. Franke, T.A.; Wixforth, A. Microfluidics for Miniaturized Laboratories on a Chip. ChemPhysChem 2008, 9, 2140-2156. [CrossRef]

174. Abate, A.R.; Poitzsch, A.; Hwang, Y.; Lee, J.; Czerwinska, J.; Weitz, D.A. Impact of inlet channel geometry on microfluidic drop formation. Phys. Rev. E 2009, 80, 026310. [CrossRef]

175. Rotem, A.; Abate, A.R.; Utada, A.S.; Van Steijn, V.; Weitz, D.A. Drop formation in non-planar microfluidic devices. Lab Chip 2012, 12, 4263-4268. [CrossRef]

176. Zhang, J.M.; Li, E.Q.; Aguirre-Pablo, A.A.; Thoroddsen, S.T. A simple and low-cost fully 3D-printed non-planar emulsion generator. RSC Adv. 2016, 6, 2793-2799. [CrossRef]

177. Hwang, Y.-H.; Um, T.; Hong, J.; Ahn, G.-N.; Qiao, J.; Kang, I.S.; Qi, L.; Lee, H.; Kim, D.-P. Robust Production of Well-Controlled Microdroplets in a 3D-Printed Chimney-Shaped Milli-Fluidic Device. Adv. Mater. Technol. 2019, 4, 1900457. [CrossRef]

178. Teh, S.Y.; Lin, R.; Hung, L.H.; Lee, A.P. Droplet microfluidics. Lab Chip 2008, 8, 198-220. [CrossRef] [PubMed]

179. Femmer, T.; Jans, A.; Eswein, R.; Anwar, N.; Moeller, M.; Wessling, M.; Kuehne, A.J. High-Throughput Generation of Emulsions and Microgels in Parallelized Microfluidic Drop-Makers Prepared by Rapid Prototyping. ACS Appl. Mater. Interfaces 2015, 7, 12635-12638. [CrossRef]

180. Van Nguyen, H.; Nguyen, H.Q.; Nguyen, V.D.; Seo, T.S. A 3D printed screw-and-nut based droplet generator with facile and precise droplet size controllability. Sens. Actuators B Chem. 2019, 296, 126676. [CrossRef]

181. Gallarate, M.; Carlotti, M.; Trotta, M.; Bovo, S. On the stability of ascorbic acid in emulsified systems for topical and cosmetic use. Int. J. Pharm. 1999, 188, 233-241. [CrossRef]

182. Laugel, C.; Rafidison, P.; Potard, G.; Aguadisch, L.; Baillet, A. Modulated release of triterpenic compounds from a O/W/O multiple emulsion formulated with dimethicones: Infrared spectrophotometric and differential calorimetric approaches. J. Control. Release 2000, 63, 7-17. [CrossRef]

183. Edris, A.; Bergnståhl, B. Encapsulation of orange oil in a spray dried double emulsion. Food/Nahrung 2001, 45, 133-137. [CrossRef]

184. Raghuraman, B.; Tirmizi, N.; Wiencek, J. Emulsion Liquid Membranes for Wastewater Treatment: Equilibrium Models for Some Typical Metal-Extractant Systems. Environ. Sci. Technol. 1994, 28, 1090-1098. [CrossRef] [PubMed]

185. Trantidou, T.; Elani, Y.; Parsons, E.; Ces, O. Hydrophilic surface modification of PDMS for droplet microfluidics using a simple, quick, and robust method via PVA deposition. Microsyst. Nanoeng. 2017, 3, 16091. [CrossRef]

186. Abate, A.R.; Krummel, A.T.; Lee, D.; Marquez, M.; Holtze, C.; Weitz, D.A. Photoreactive coating for high-contrast spatial patterning of microfluidic device wettability. Lab Chip 2008, 8, 2157-2160. [CrossRef]

187. Abate, A.R.; Weitz, D.A. High-Order Multiple Emulsions Formed in Poly(dimethylsiloxane) Microfluidics. Small 2009, 5, 2030-2032. [CrossRef] 
188. Morimoto, Y.; Kiyosawa, M.; Takeuchi, S. Three-dimensional printed microfluidic modules for design changeable coaxial microfluidic devices. Sens. Actuators B Chem. 2018, 274, 491-500. [CrossRef] 